\title{
Development of an Uncertainty Quantification Predictive Chemical Reaction Model for Syngas Combustion
}

\author{
N. A. Slavinskaya, ${ }^{* \dagger}$ M. Abbasi, ${ }^{\dagger}$ J. H. Starcke, ${ }^{\dagger}$ R. Whitside, ${ }^{\dagger}$ A. Mirzayeva, ${ }^{\dagger}$ U. Riedel, ${ }^{\dagger}$ W. Li, ${ }^{\dagger}$ J. Oreluk, $^{\ddagger}$ \\ A. Hegde, ${ }^{\ddagger}$ A. Packard, ${ }^{\ddagger}$ M. Frenklach, ${ }^{*} \neq \odot$ G. Gerasimov, ${ }^{\S}$ and O. Shatalov ${ }^{\S}$ \\ ${ }^{\dagger}$ Institute of Combustion Technology, German Aerospace Center (DLR), 70569 Stuttgart, Germany \\ ${ }^{\ddagger}$ Department of Mechanical Engineering, University of California, Berkeley, Berkeley, California 94720, United States \\ ${ }^{\S}$ Institute of Mechanics, M. V. Lomonosov Moscow State University, Michurinskii Prospekt, 1, 119192 Moscow, Russia
}

Supporting Information

\begin{abstract}
An automated data-centric infrastructure, Process Informatics Model (PrIMe), was applied to validation and optimization of a syngas combustion model. The Bound-to-Bound Data Collaboration (B2BDC) module of PrIMe was employed to discover the limits of parameter modifications based on uncertainty quantification (UQ) and consistency analysis of the model-data system and experimental data, including shock-tube ignition delay times and laminar flame speeds. Existing syngas reaction models are reviewed, and the selected kinetic data are described in detail. Empirical rules were developed and applied to evaluate the uncertainty bounds of the literature experimental data. The initial $\mathrm{H}_{2} / \mathrm{CO}$ reaction model, assembled from 73 reactions and 17 species, was subjected to a B2BDC analysis. For this purpose, a dataset was constructed that included a total of 167 experimental targets and 55 active model parameters. Consistency analysis of the composed dataset revealed disagreement between models and data. Further analysis suggested that removing 45 experimental targets, 8 of which were self-inconsistent, would lead to a consistent dataset. This dataset was subjected to a correlation analysis, which highlights possible directions for parameter modification and model improvement. Additionally, several methods of parameter optimization were applied, some of them unique to the B2BDC framework. The optimized models demonstrated improved agreement with experiments compared to the initially assembled model, and their predictions for experiments not included in the initial dataset (i.e., a blind prediction) were investigated. The results demonstrate benefits of applying the B2BDC methodology for developing predictive kinetic models.
\end{abstract}

\section{INTRODUCTION}

Developing predictive reaction models for complex chemical systems requires integration of large amounts of theoretical, computational, and experimental data collected by numerous researchers. The model fidelity is judged by its prior information, the quality of chemical kinetic data used (e.g., models developed from "first principles", with minimal parameter fitting), and from posterior information, comparison of the model predictions to available experimental observations. The latter is taken as model validation, and the observed differences drive modification of the model and design of new experiments. This process, model update $\Rightarrow$ validation $\Rightarrow$ new experiments/ theory $\Rightarrow$ model update, conducted iteratively, is generally accepted as the core of the scientific method. ${ }^{1}$ The key challenge is to organize this iterative process in such a manner as to ensure its convergence and to find methods that increase the convergence rate. $^{2}$

The model update performed in isolation, i.e., on the basis of an individual set of data, cannot guarantee the convergence and rather leads to ineffectual proliferation of competing reaction "mechanisms". ${ }^{2}$ Combining larger amounts of data, from multiple sources, of diverse nature, probing different aspects of the system in question, even in an indirect way, was reasoned to compensate for the incompleteness of an individual set of measurements. $^{2-4}$ This premise has found support in the success of the GRI-Mech project. ${ }^{5}$ The initial numerical framework centered on least squares optimization, minimizing deviations between model predictions and experimental targets by fitting reaction model rate parameters within their respective uncertainty ranges. ${ }^{3,6-9}$ This protocol has now been followed by others. ${ }^{10-13}$

The least squares optimization, on its own, does not lead to a fully satisfactory solution. In addition to numerical difficulties of finding a global minimum in a multi-dimensional parameter space, the presence of experimental uncertainties and nonrigorous nature of target weights makes the objective minimum essentially a random outcome. ${ }^{2}$ Following this approach recreates anew the reality of "embarrassment of success": accumulation of now optimized mechanisms, as evidenced by a recent comparison of 16 mechanisms of syngas combustion. ${ }^{14}$ None of the 16 mechanisms could be identified as performing best under all of the conditions tested, and the authors resorted to producing a new optimized mechanism, ${ }^{12}$ which they described as the one "to provide the best reproduction of the experimental data". However, the results of the present study will show that there exists a parameter set that outperforms that

Special Issue: In Honor of Professor Brian Haynes on the Occasion of His 65th Birthday

Received: September 12, 2016

Revised: January 20, 2017

Published: January 24, 2017 


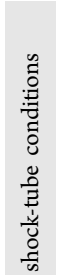

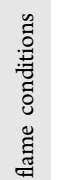

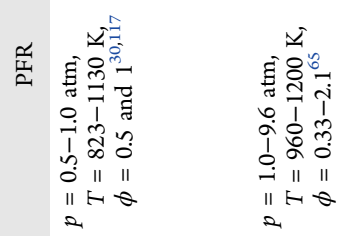

$\underline{\tilde{m}}$

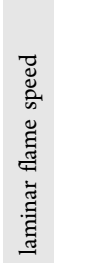

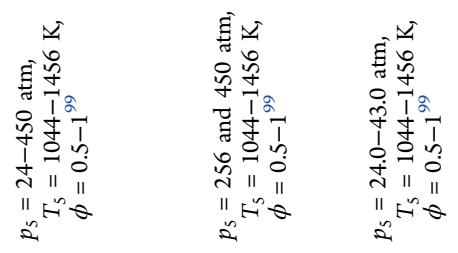

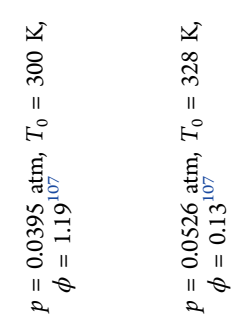

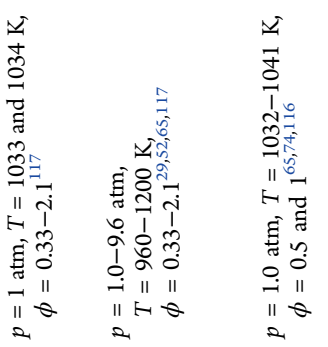

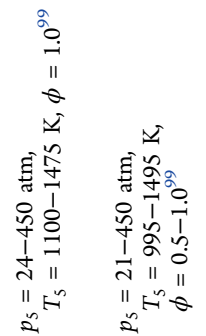

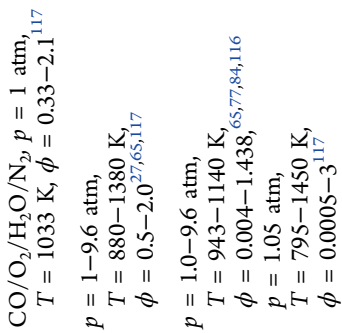

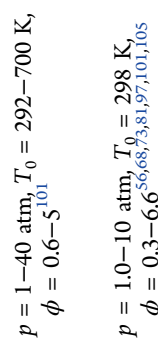
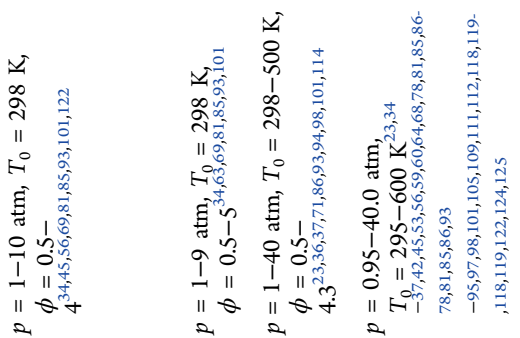

造

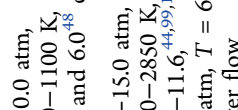

I

a

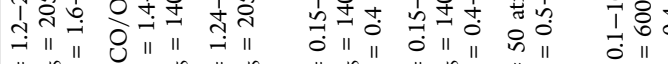

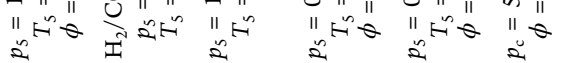

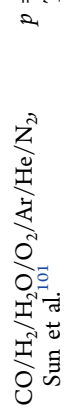

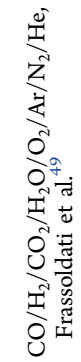

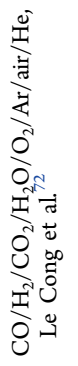

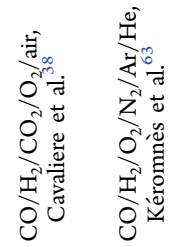

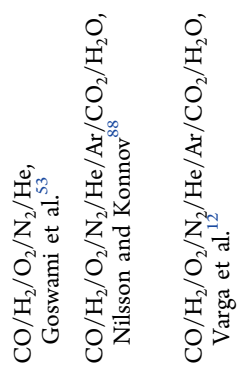


one of Varga et al. ${ }^{12}$ The point here is not which mechanism performs better but how to ensure the convergence of model improvement with the immediate benefits to society.

A roadmap for a convergent approach was suggested by the introduction of Process Informatics, ${ }^{2}$ shifting the focus to data and data uncertainty. The centerpiece of this framework is a dataset, ${ }^{15}$ a properly organized collection of observed experimental targets, their respective uncertainties, and model(s) predicting the target values as function(s) of active variables (typically model parameters) within their respective ranges of uncertainty. The numerical part of the framework is to transfer the parameter and target uncertainties to the uncertainty of model prediction.

In the present work, we continued development of this framework while applying it to a system of immediate practical interest, syngas combustion. Specifically, we used the data warehousing and functionality of an automated data-centric infrastructure, Process Informatics Model (PrIMe).,16,17 Original PrIMe data models and archival formats ${ }^{16,17}$ were employed, because they provide a more comprehensive capture of the ontology and uncertainty of the data, as compared to recently suggested "modifications" 12 that managed to lose some of this critical capability without adding anything new.

For the numerical analysis, we employed the methodology developed in a series of studies ${ }^{2,9,15,17-21}$ and termed Bound-toBound Data Collaboration (B2BDC). It is a deterministic framework of uncertainty quantification (UQ). The approach deploys semi-definite programming algorithms, ${ }^{22}$ where the initial bounds on unknowns are combined with initial bounds of experimental data to produce new uncertainty bounds for the unknowns that are consistent with the data and, finally, deterministic uncertainty bounds for prediction in new settings. The latter is accomplished in a single step, in a direct transfer of uncertainty from its prior knowledge to prediction, thus assuring the smallest value of uncertainty in prediction. ${ }^{20}$ Perhaps the most distinguishing feature of the B2BDC is validation of the data-model system through computation of the consistency measure of the dataset ${ }^{18}$ and its sensitivities to the prior uncertainty bounds. ${ }^{19}$ This methodology has been applied to several systems, ${ }^{18,23,24}$ and it allowed us to identify problematic experimental data in the present study.

The key difference between the prior (GRI-Mech) optimization framework and the current PrIMe-B2BDC one is in the outcome: a single optimized model is just one instance of an infinite number of such possible models. The B2BDC framework identifies all acceptable models, i.e., models that satisfy the uncertainty information on the entire dataset. Working on and enriching the same (communal) dataset is the vehicle for the convergence. At any instance of the continuously evolving dataset, one can make direct predictions on the dataset or use the dataset for building specific instances of models, optimal in one way or another. We demonstrate both of these applications in the present study.

The chemical reaction system that we consider in the present study is the $\mathrm{H}_{2} / \mathrm{CO}$ oxidation, which is a part of the DLR hydrocarbon reaction mechanism and database. ${ }^{25,26}$ The development of reaction models for larger hydrocarbons may require modification of the $\mathrm{H}_{2} / \mathrm{CO}$ system. Continuous reoptimization, in addition to problems discussed above, becomes a tedious endeavor, and the increasing number of optimization variables may lead to numerical difficulties. Freezing some parameters, as was practiced in the past and reintroduced recently, ${ }^{14}$ leads to the loss of information and 
becomes a source of artificial controversies. ${ }^{2,15}$ The B2BDC methodology applied in the present analysis avoids such problems.

The paper is organized as follows: In section 2, we review syngas model development, focusing on work performed in recent years. Section 3 presents a brief overview of B2BDC, which provides the foundation for the analyses described in the paper. We then proceed, in section 4, with a description of the reaction model, experimental targets, and their associated uncertainties. Presentation and discussion of the numerical results is given in section 5 . We conclude with section 6 , summarizing the present experience and suggesting further directions for improving the predictive ability of modeling syngas combustion.

\section{EXPERIMENTAL DATA}

As mentioned in the Introduction, the data-model system that we consider in the present study is a chemical reaction system of the syngas oxidation. A mixture of hydrogen and carbon monoxide, commonly called synthesis gas or syngas, can be obtained from natural gas, coal, petroleum, biomass, and even organic waste. Syngas is used as a direct fuel for clean combustion in electricity generation from coal, petroleum coke, or heavy residuals in an integrated gasification combined cycle (IGCC). In recent years, the role of syngas in sustainable combustion processes and promising syngas utilization for power generation triggered further characterization of the $\mathrm{H}_{2} / \mathrm{CO}$ combustion system. Also, the $\mathrm{H}_{2} / \mathrm{CO}$ oxidation chemistry is the principal building block in the hierarchy of hydrocarbon oxidation models.

A large amount of thermokinetic and experimental data has appeared for this system in recent years..$^{10,12,16,23,25-124}$ Table 1 summarizes the most established, in our opinion, $\mathrm{H}_{2} / \mathrm{CO}$ reaction models with experimental validation data that have been used.

One of the early investigations of $\mathrm{H}_{2} / \mathrm{CO}$ chemistry, which underlies most modern models, is the study of Yetter et al. ${ }^{116}$ In their study, ${ }^{116}$ previous investigation results were analyzed and integrated in a $\mathrm{CO} / \mathrm{H}_{2} / \mathrm{O}_{2}$ reaction mechanism, which was tested against a wide range of available experimental data obtained from shock-tube and flow reactors ${ }^{30,44,117}$ (Table 1). The model was validated over a combined temperature range of $823-2870 \mathrm{~K}$, fueloxidizer equivalence ratios $\varphi=0.5-6.0$, and pressures $p=0.3-$ $2.2 \mathrm{~atm}$. The kinetics were analyzed in three temperature regimes (low, intermediate, and high), where different reaction sets control the radical pool. The high-temperature regime is associated with the $\mathrm{H}, \mathrm{O}$, and $\mathrm{OH}$ radicals, while the low-temperature regime is dominated by $\mathrm{HO}_{2}$ and $\mathrm{H}_{2} \mathrm{O}_{2}$. The intermediate-temperature regime serves as a transition zone, in which the concentrations of $\mathrm{H}, \mathrm{O}, \mathrm{OH}, \mathrm{HO}_{2}$, and $\mathrm{H}_{2} \mathrm{O}_{2}$ intermediates are all nearly the same order of magnitude. Moreover, this regime embodies the explosion limits, which separate the slow reaction (chain propagation) from the fast reaction (chain branching). Consequently, system pressure and composition affect the limits of these regimes. Uncertainties in the kinetic and thermochemical parameters were analyzed.

The updated $\mathrm{H}_{2} / \mathrm{CO}$ subset of the Leeds methane oxidation mechanism ${ }^{120}$ implements reaction kinetic and thermodynamic data along with the results (at the time of publication) from $\mathrm{H}_{2} /$ air and wet $\mathrm{CO} / \mathrm{air}$ combustion mechanisms. The updated mechanism was tested against hydrogen oxidation and $\mathrm{H}_{2} / \mathrm{CO}$ oxidation experiments ${ }^{31,32,46,47,50,62,70,81,106}$ (Table 1). Uncertainties of the simulation results, caused by the uncertainties in the kinetic parameters and the heats of formation, were analyzed.

Davis et al. ${ }^{10}$ proposed a $\mathrm{H}_{2} / \mathrm{CO}$ kinetic model based on the GRIMech 3.0 model. ${ }^{5}$ They presented a comprehensive literature review of kinetic data and performed model optimization within the uncertainty bounds of the relevant rate parameters with respect to 36 targets: experimental data for ignition delays, laminar flame speeds, and species profiles of $\mathrm{H}_{2}$ and $\mathrm{CO}$ measured in flames and flow reactors. ${ }^{44,65,81,105}$ Their model ${ }^{10}$ predicts the observed $\mathrm{H}_{2} / \mathrm{CO}$ oxidation experimental data over the combined range of $T=298-2870 \mathrm{~K}, \varphi=0.33-6.0$, and $p=1.0-9.6 \mathrm{~atm}$ (Table 1).

Saxena and Williams ${ }^{96}$ tested a relatively small detailed mechanism for propane combustion ${ }^{76}$ to predict hydrogen and carbon monoxide combustion. The performed study resulted in the revision of some rate parameters, the elimination of one initiation step in the hydrogen oxidation mechanism, and the addition of an initiation step for carbon monoxide oxidation. With these alterations, a reasonable agreement was obtained with measured burning velocities, diffusion flame extinction conditions (for $\mathrm{H}_{2} / \mathrm{O}_{2}$ ), and autoignition times ${ }^{44,50,74,81}$ (Table 1). Combined parameter ranges were temperature of 298 and $1400-2870 \mathrm{~K}, \varphi=0.4-6.0$, and pressures $p=0.15-2.2 \mathrm{~atm}$.

$\mathrm{Li}$ et al. ${ }^{76}$ and Chaos et al. ${ }^{39}$ updated the model used in the study. ${ }^{116}$ $\mathrm{Li}$ et al. ${ }^{76}$ revised the $\mathrm{H}_{2} / \mathrm{CO}$ sub-mechanism in a reaction model for $\mathrm{CO} / \mathrm{H}_{2} \mathrm{O} / \mathrm{H}_{2} / \mathrm{O}_{2}, \mathrm{CH}_{2} \mathrm{O}$, and $\mathrm{CH}_{3} \mathrm{OH}$ oxidation and modified it based on the published measured data for ignition delays, laminar flame speeds, and plug-flow concentration profiles $44,50,59,65,81,84,117$ (Table 1). Modifications of reaction rate coefficients responsible for the formation of $\mathrm{CO}_{2}$ and $\mathrm{CO}$ were extensively investigated and optimized with weighted least square fits of available experimental measurements. This resulted in significantly closer prediction of the experimental observations. Chaos et al. ${ }^{39}$ investigated important features of $\mathrm{H}_{2} / \mathrm{CO}$ combustion at high pressures and relatively low temperatures and also effects of surfaces, trace impurities, and contaminants. The paper reviewed experimental efforts in the highpressure syngas oxidation and discussed the kinetic changes proposed in the literature for improving predictions of new data. Further $\mathrm{H}_{2} / \mathrm{CO}$ kinetic improvements related to investigations ${ }^{76,116}$ were also proposed on the basis of recent high-pressure experimental observations ${ }^{83,99}$ (Table 1) and associated theoretical works. The authors noted the need for careful analysis of data collected at high pressures.

Sun et al. ${ }^{101}$ developed a kinetic mechanism to model the measured laminar flame speeds for $\mathrm{CO} / \mathrm{H}_{2} /$ air and $\mathrm{CO} / \mathrm{H}_{2} / \mathrm{O}_{2} / \mathrm{He}$ mixtures at different equivalence ratios and pressures up to $40 \mathrm{~atm}$. The rate coefficient of reaction $\mathrm{CO}+\mathrm{HO}_{2} \rightarrow \mathrm{CO}_{2}+\mathrm{OH}$ was calculated on the basis of $a b$ initio quantum chemistry and the canonical transition state theory. The elaborated mechanism was successfully used to model the experimental data ${ }^{48,101,117}$ (Table 1).

Frassoldati et al. ${ }^{49}$ extended the previous kinetic model of Ranzi et al. ${ }^{126}$ They revised and validated a detailed kinetic model of $\mathrm{H}_{2} / \mathrm{CO}$ combustion with particular focus on $\mathrm{NO}_{x}$ formation and especially the interactions of the syngas system with nitrogen species. ${ }^{49}$ Their paper offers a critical collection of experimental data $^{29,41,44,52,56,65,68,73,81,97,99,101,105,107,113,117,121}$ and a kinetic model capable of simulating the combustion of syngas mixtures and the formation of pollutant species across a wide range of conditions, with particular emphasis on high pressures (Table 1).

A syngas mechanism proposed by Le Cong et al. ${ }^{72}$ is the $\mathrm{H}_{2} / \mathrm{CO}$ sub-model of the detailed combustion kinetic model for $\mathrm{H}_{2} / \mathrm{CO} /$ $\mathrm{CH}_{2} \mathrm{O} / \mathrm{CH}_{3} \mathrm{OH} / \mathrm{CH}_{4}$ systems. Their updated kinetic scheme was successfully validated against a large set of data for $\mathrm{CO}$ and $\mathrm{H}_{2} / \mathrm{CO}$ combustion $^{41,65,74,81,85,99,101,107,116,121,122}$ (Table 1). The effects of total pressure, equivalence ratio, and $\mathrm{H}_{2} / \mathrm{CO}$ concentrations on flame speeds are well-predicted. Also, the kinetics of oxidation of $\mathrm{CO}$ and $\mathrm{H}_{2} / \mathrm{CO}$ in a turbulent flow reactor, a jet-stirred reactor (JSR), and the high-pressure shock-tube experiments were successfully reproduced.

Cavaliere et al. ${ }^{38}$ adapted the mechanism of Saxena and William ${ }^{96}$ to intermediate pressures based on the experimental measurements ${ }^{61,90,91}$ (Table 1). The $\mathrm{H}_{2} / \mathrm{CO}$ mechanism was tested over a temperature range of $600-1400 \mathrm{~K}$ and a pressure range of 1.0-15.0 atm. $\mathrm{H}_{2} \mathrm{O}_{2}+$ $\mathrm{M}=\mathrm{OH}+\mathrm{OH}+\mathrm{M}$ and $\mathrm{H}+\mathrm{H}_{2} \mathrm{O}_{2}=\mathrm{HO}_{2}+\mathrm{H}_{2}$ reactions were found to be the rate-controlling steps for the prediction of the ignition time at high pressures and low temperatures.

A detailed $\mathrm{H}_{2} / \mathrm{CO} / \mathrm{O}_{2}$ reaction mechanism of Kéromnès et al. ${ }^{63}$ is based on the former $\mathrm{H}_{2} / \mathrm{O}_{2}$ mechanism of Ó Conaire et al., ${ }^{89}$ with some updates to reflect new experimental data obtained in this work. The reaction sequence $\mathrm{H}_{2}+\mathrm{HO}_{2}=\mathrm{H}+\mathrm{H}_{2} \mathrm{O}_{2}$ followed by $\mathrm{H}_{2} \mathrm{O}_{2}$ $(+\mathrm{M})=\mathrm{OH}+\mathrm{OH}(+\mathrm{M})$ was found to play a key role in the hydrogen ignition under high-pressure and intermediate- to high-temperature conditions. At low pressures (of the order of $1 \mathrm{~atm}$ ) and low temperatures 
Table 2. Evaluation of Uncertainty Intervals for Selected Shock-Tube Experiments ${ }^{a}$

\begin{tabular}{|c|c|c|c|c|c|c|c|c|c|c|c|}
\hline \multirow[b]{2}{*}{$\begin{array}{c}\text { length } \\
(\mathrm{m})\end{array}$} & \multicolumn{3}{|c|}{ driven-section dimensions } & \multirow[b]{2}{*}{$\begin{array}{l}\text { temperature interval } \\
(\mathrm{K})\end{array}$} & \multirow[b]{2}{*}{$\begin{array}{c}\text { error } \\
(\%)\end{array}$} & \multirow[b]{2}{*}{$\begin{array}{l}\text { pressure } \\
\text { (atm) }\end{array}$} & \multirow[b]{2}{*}{$\begin{array}{c}\text { error } \\
(\%)\end{array}$} & \multirow[b]{2}{*}{ dilution } & \multirow[b]{2}{*}{$\begin{array}{c}\text { error } \\
(\%)\end{array}$} & \multirow[b]{2}{*}{$t_{\text {meas }}(\mu \mathrm{s})$} & \multirow[b]{2}{*}{$\begin{array}{c}\text { error } \\
(\%)\end{array}$} \\
\hline & $\begin{array}{c}\text { error } \\
(\%)\end{array}$ & $\begin{array}{l}\text { internal diameter } \\
(\mathrm{cm})\end{array}$ & $\begin{array}{c}\text { error } \\
(\%)\end{array}$ & & & & & & & & \\
\hline$>8$ & & $>10$ & & $T<1000$ & +5 & $p>15$ & +5 & yes & & $0-50$ & +5 \\
\hline \multirow[t]{4}{*}{$<8$} & +5 & $<10$ & +5 & $T>1600$ & +5 & $p>30$ & +10 & none & +5 & $50-500$ & +0 \\
\hline & & & & & & every 15 & +5 & & & $500-1000$ & +5 \\
\hline & & & & & & & & & & $1000-1500$ & +10 \\
\hline & & & & & & & & & & every 500 & +5 \\
\hline
\end{tabular}

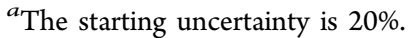

(below $1000 \mathrm{~K}$ ), the process is controlled by the competition between the chain-branching reaction $\mathrm{H}+\mathrm{O}_{2}=\mathrm{O}+\mathrm{OH}$ and the chainpropagating reaction $\mathrm{H}+\mathrm{O}_{2}(+\mathrm{M})=\mathrm{HO}_{2}(+\mathrm{M})$. The mechanism accurately reproduces new high-pressure experimental data (ignition delay times and flame speed) relevant to gas turbine conditions ${ }^{24}$ as well as previous experimental data. ${ }^{34,45,56,63,69,81,85,93,101,122}$

The $\mathrm{H}_{2} / \mathrm{CO}$ kinetic mechanism of Goswami et al. ${ }^{53}$ is based on the $\mathrm{H}_{2} / \mathrm{O}_{2}$ mechanism of Konnov ${ }^{66}$ and includes recently evaluated rate coefficients. The $\mathrm{CO}$ set of reactions was taken from Konnov 0.6 version, ${ }^{67}$ with few modifications. After validation against new measurements, the kinetic mechanism was further validated using experimental data available in the recent literature for lean and rich mixtures at elevated pressures. These data included laminar burning velocities, ${ }^{34,63,69,81,85,93,101}$ ignition delay times, ${ }^{63}$ and speciation measurements. $^{117}$

The kinetic mechanism of Nilsson and $\mathrm{Konnov}^{88}$ is a further expansion of the $\mathrm{H}_{2} / \mathrm{O}_{2}$ mechanism recently proposed by Alekseev et al. $^{28}$ The reaction rate coefficients were chosen based on an extensive literature review. Particular attention in this mechanism was given to the chemistry of $\mathrm{HOCO}$, produced from the $\mathrm{CO}+\mathrm{OH}$ reaction. It must be pointed out that most available syngas mechanisms do not include HOCO, since it is only expected to be of importance at some extreme high-pressure and low-temperature conditions. The mechanism was validated against a wide range of experimental data, including ignition, flame structures, and laminar flame speeds, $23,27,36,37,61,65,7,86,93,94,98,99,101,104,114,117$ with particular attention given to laminar burning velocities. Variations in the $\mathrm{H}_{2} / \mathrm{CO}$ ratio, pressure, temperature, and diluents $\left(\mathrm{CO}_{2}, \mathrm{H}_{2} \mathrm{O}\right.$, and $\left.\mathrm{N}_{2}\right)$ were considered. In comparison to the mechanism of Kéromnès et al., ${ }^{63}$ this mechanism gives better agreement with experimental laminar burning velocities at rich conditions.

Varga et al. ${ }^{12}$ developed an optimized joint hydrogen and syngas combustion mechanism. The model of Kéromnès et al. ${ }^{63}$ was updated with the recently optimized hydrogen combustion mechanism of Varga et al. ${ }^{11}$ and further optimized using a global parameter optimization method. ${ }^{127}$ The experimental data included ignition delay times measured in shock tubes and rapid compression machines (1723 targets and 156 data sets), burning velocity measurements (2311 targets and 256 data sets), and species profiles measured in shock tubes, flow reactors (968 targets and 53 data sets), and JSRs (103 concentration targets and 11 data sets). Directly measured rate coefficients of 15 reactions were also used. A total of 48 Arrhenius parameters and 5 third-body collision efficiencies of 18 elementary reactions were optimized. The optimized mechanism was compared to 19 recent hydrogen and syngas combustion mechanisms and was shown to provide the closest reproduction of the used experimental data.

The experimental data applied for model validation in the present study are listed in the last row of Table 1 and in Tables S1 and S2 of the Supporting Information. Only ignition delays and laminar flame speeds were used in the analysis: these experimental measurements generally have lower uncertainty in comparison to species concentration profiles. Also, the quantity of experimental ignition delay and laminar flame speed measurements greatly exceeds those of species concentrations. Having more data included in the analysis should provide more objective statistics and more meaningful model validation.
The importance of uncertainty in chemical kinetic problems prompted development of methods for kinetic model optimization and uncertainty quantification. ${ }^{2,9,15,17-21,127-130}$ In the present work, we used the methodology of B2BDC, $2,9,15,17-21,127-130$ which is briefly described next. We then proceed with a description of the newly constructed dataset, i.e., the selected experimental targets, reaction model, and associated uncertainties, detailing the methodology adopted for evaluation of the uncertainties. This will be followed by presentation and discussion of the numerical results.

\section{THEORETICAL BACKGROUND: B2BDC}

$\mathrm{B} 2 \mathrm{BDC}$ is an optimization-based framework for combining models and experimental data from multiple sources to explore their collective information content. $2,9,15,17-21,127-130$ The approach can decisively indicate whether related experimental data are consistent with each other within a specified chemical kinetic model, explore sources of inconsistency, discriminate among differing models, make model interval predictions, and analyze sensitivity of uncertainty propagation. We begin by reiterating some key definitions.

3.1. Quantities of Interest (Qol). QoI is a collection of experimental observations of physical processes, coupled with respective uncertainties, assessed as lower and upper bounds on the observed values, i.e., $L_{e}$ and $U_{e}$ for each eth QoI. Each physical process can be represented by a common chemical reaction model, $C(x)$, and a reactor physics model, $R_{e}$, with the two forming a combined numerical model that we refer to as $M_{e}(x)$, with prior knowledge on the domain of parameters thus constraining each parameter $x$ to an interval $\left[x_{\min }, x_{\max }\right]$ and all together to a hypercube $x \in H$.

A key requirement for $\mathrm{B} 2 \mathrm{BDC}$ is the formulation of a dataset, which entails creation of dataset units for all QoI, $e=1$, 2 ,..., from a common kinetic model, experimental observations, and their uncertainties.

The computational model $M_{e}(x)$ must produce outputs that are consistent with the reported QoI uncertainties. Hence, additional constraints that the true model parameters must satisfy are

$$
L_{e} \leq M_{e}(x) \leq U_{e} \quad \text { for all } e
$$

The subset of $H$ satisfying (eq 1 ) is called the feasible set, $F$, of parameters; i.e., all model parameter values that jointly satisfy all of the prior information and all of their model predictions are consistent with the reported experimental observations. The integral part of the B2BDC framework is approximation of the $M_{e}(x)$ outputs for given QoI by quadratic (or rational quadratic) surrogate models, ${ }^{9} M_{e}(x)$, and hence, the feasible set can be defined as

$$
F=x \in H: L_{e} \leq M_{e}(x) \leq U_{e} \forall e
$$


where $M_{e}(x)$ designates a surrogate model of eth QoI. A parameter value that is not in $F$ is at odds with at least one of these constraints.

In this way, the first "bound" in the "bound-to-bound" nomenclature is associated with (a) the form of the prior information, namely, that the true model parameters must be both contained in the parameter hypercube $H$ (in the form of bounds on the components), and (b) the true parameters must result in model predictions of all QoI (i.e., training experiments) that are within the measurement bounds declared by the experimenters, namely, $L_{e} \leq M_{e}(x) \leq U_{e}$ for all $e$. Together, these are the "bounds" that define F. Subsequent B2BDC computations (model parameter analysis and optimization) can be performed only if the feasible set $F$ is non-empty.

3.2. DataSet Consistency. Dataset consistency is analysis that examines the existence of a feasible parameter vector by determining the consistency measure of dataset $D .^{18}$

$$
\begin{aligned}
C_{D} & =\max _{\gamma, x \in H} \gamma, \text { subject to }(\text { for all } e):(1-\gamma) \frac{L_{e}-U_{e}}{2} \\
& \leq M_{e}(x)-\frac{L_{e}+U_{e}}{2} \leq(1-\gamma) \frac{U_{e}-L_{e}}{2}
\end{aligned}
$$

In this definition, the original constraints (eq 1) are augmented with a scalar relaxation parameter, $\gamma$, where positive values of $\gamma$ imply tightening of the constraint (dataset is consistent) and negative values imply loosening (dataset is inconsistent). The consistency measure, $C_{D}$, quantifies how much the constraints can be tightened while still ensuring the existence of a set of parameter values whose associated model predictions match (within the bounds) the experimental QoI.

3.3. Model Prediction. Model prediction is the prediction interval for property $P$ by model $M_{P}$ that is consistent with all of the model/observation pairs in the dataset. The B2BDC computation expresses that, into two optimization problems for the lower and upper interval end points, $L_{P}$ and $U_{P}$

$$
\begin{aligned}
& L_{P}=\min _{x \in F} M_{P}(x) \\
& U_{P}=\max _{x \in F} M_{P}(x)
\end{aligned}
$$

The length $U_{P}-L_{P}$ quantifies the amount of uncertainty in $M_{P}$ value conditioned on the fact that the true parameter vector is contained in the feasible set $F$. The mathematical methodology of B2BDC is invoked for the constrained optimization of a function of interest $f$ over the feasible set $F$. The computed $f_{\min }$ and $f_{\max }$ constitute the "to-bound" aspect: the bounds that describe the prior information and the bounds on experimental observations that are mapped into bounds on prediction. The mathematical details for polynomial surrogate models can be found in the study by Seiler et al. ${ }^{21}$

In what follows, a consistent dataset for the studied $\mathrm{H}_{2} / \mathrm{CO}$ data-model system will be produced and tested for consistency. The kinetic model will be optimized over the feasible region of the parameter space of the $\mathrm{H}_{2} / \mathrm{CO}$ data-model system using methods described in the study by You et al. ${ }^{130}$ Optimization constrained to the feasible set, methods LS-F and $1 \mathrm{~N}-\mathrm{F},{ }^{130}$ ensures that all model predictions fall within the uncertainties of experimental QoI. Method LS-F uses a weighted least squared objective, while $1 \mathrm{~N}-\mathrm{F}$ is a one-norm minimization that aims at the smallest number of parameters to be changed. We also employed, for comparison, method LS-H, which is a least squared minimization constrained to the prior knowledge hypercube, $H$.

\section{DLR-SYNG DATASET}

A key requirement for the analysis is the formulation of a dataset, which entails creation of dataset units from experimental observations and a common kinetic model. A dataset unit consists of the measured observation, uncertainty bounds of the measurement, and a model that transforms active parameter values into a prediction for the measured QoI. The active model parameters were multipliers to the rate coefficients, denoted hereafter by $\lambda$; they relate to parameters $x$ in section 3 through logarithmic transformation, namely, $x=\ln \lambda$. The reasoning behind using only multipliers is discussed in section 5.2. Active parameters were identified via sensitivity analysis. ${ }^{9}$ A quadratic response surface was developed for each QoI in terms of its own set of active parameters via computer experiments performed by sampling $x$ from $H$, arranged to a factorial design. ${ }^{9}$ Once developed, the dataset can be subjected to rigorous numerical analysis.

4.1. Ignition Delay Time Qol. To account for syngas ignition, we selected a set of the shock-tube syngas ignition measurements $^{51,58,61,69,79,80,82,83,90,91,104,108,130}$ that covers a wide range of temperatures $(800-2500 \mathrm{~K})$, pressures $(0.5-$ 50 bar), and equivalence ratios $(\varphi=0.5-1.50)$. Evaluation of $L_{e}$ and $U_{e}$ for each QoI was accomplished by creating an empirical rule, which is motivated below.

The fuel ignition produced in a shock tube is a combination of several physical and chemical phenomena. Fluid-flow patterns developed behind the shock that cannot be assumed homogeneous and uniform are classified as "non-idealities" of shocktube experiments. ${ }^{79,131-139}$ Facility-dependent effects and energy-release phenomena can increase the non-idealities and influence the instrument readings, thus adding to the uncertainty of experimental data. Although the presence of the non-idealities in shock tubes have been well-documented, ${ }^{79,132-136,138-140}$ there are no simple protocols to quantitatively assess their impact on measured ignition delays. However, it is this assessment that may determine the usefulness of the experimental data for model validation. The issue is not just a few percent uncertainty in the measured value but realization that the observed phenomenon can be an expression of mechanisms other than chemical kinetics. The origin of such a conclusion goes to the work of Tony Oppenheim, who introduced distinction between mild and strong ignition; ${ }^{140}$ the latter is driven essentially by chemistry, but the former is not. The results of the present study, supported by a rigorous quantitative assessment, point further to the paramount importance of considering such aspects for suitability of QoI selection for model validation.

Unfortunately, reports of experimental observations are seldom accompanied by uncertainty quantification, and when such information is present, it usually reflects an assessment of aleatoric uncertainty and not epistemic uncertainty. For the purpose of dataset construction, we designed an empirical protocol for a priori assignment of the uncertainty bounds to the measured observations included in the dataset. For this purpose, the strongest non-ideality phenomena were determined across the investigations, and the facility- and fuel-related factors that affect these phenomena were identified. The influence of the operating conditions (pressure, temperature, and equivalent ratios) on these factors was taken into account. The dominant facility-related non-ideality phenomena were attributed to two gas dynamics effects: (i) boundary layer formation 
after shock passing (resulting in hydro- and thermoinhomogeneities behind the shock wave) and (ii) post-shock compression (interaction of the reflected shock wave with the contact surface). The dominant fuel-related non-ideality phenomenon, as discussed above, is energy-release: the weakignition regime (non-uniform/distributed ignition) and the strong-ignition regime (initiated by autoignition at the end wall of the shock tube). ${ }^{135,140}$ The factors that influence these phenomena are length and diameter of the driven section, duration of the reaction, mixture dilution, and nature of carrier gas (CG). The operating conditions enhance the influence of these factors. For instance, the non-uniform/distributed ignition accomplished with flame propagation will prevail at lower temperatures, $T<1000 \mathrm{~K}^{135,136}$

In our empirical protocol, the "ideal case" (vanishing influence of "non-idealities") was defined as measurements performed in a shock tube with the driver-section length of $\geq 3.0 \mathrm{~m}$ and the driven-section length of $\geq 8.0 \mathrm{~m}$ with an internal diameter (most important factor) larger than $10.0 \mathrm{~cm}$, in a temperature interval of $1000-1600 \mathrm{~K}$, pressure less than $15 \mathrm{~atm}$, a fuel/air ratio exceeding 0.3 , dilution with a monatomic gas 1:2 or higher, and the measured ignition delay time $t_{\text {meas }}$ lower than $500 \mu \mathrm{s}^{79,131-139}$ The systematic (epistemic) experimental uncertainty caused mostly by temperature, pressure, and concentration measurements as well as measurement location was estimated as $15 \%$. Radical impurities were evaluated as extra 5\% uncertainty. ${ }^{139}$ Formulated in this manner, the "starting point" for identification of the shocktube data uncertainty becomes $20 \%$. Deviations from the "ideal case" conditions were evaluated by adding a $5 \%$ uncertainty for each criterion not satisfied to the ideal case. For a measured ignition delay time longer than $1000 \mu \mathrm{s}$ (mostly at low temperatures), $5 \%$ uncertainty was added per every $500 \mu \mathrm{s}$. At longer measurement times, the influence of the gas dynamic effects on the ignition process (which can be in the weakignition regime) is increased. At such conditions, if the experimental data uncertainty were evaluated by the authors to be larger than $20 \%$, the evaluation of the authors was taken as the starting point; otherwise, if the reported uncertainties were lower than $20 \%$, we assumed the starting point to be $20 \%$. Our uncertainty evaluation rules are documented in Table 2. Ignition delay targets selected for analysis and their evaluated uncertainties can be found in Tables $S 1$ and $S 3$ of the Supporting Information.

4.2. Laminar Flame Velocity Qol. To represent flame propagation conditions, we selected a set of flame velocities at $0.1-0.5 \mathrm{MPa}$ that have been investigated using a variety of techniques (Table 1). The laminar flame speeds included in the present dataset were taken from studies ${ }^{42,53-57,71,75,81,85,86,101,102,110,111,114,115,119}$ (Table S2 of the Supporting Information). They were selected to cover the full range of operating conditions available in the literature. The flame speeds measured at high pressures are relatively scarce. Experimentalists estimate the current uncertainties in laminar flame speed measurements to be in a range of about 5-10\%, increasing with pressure $(>0.5 \mathrm{MPa})$ and fuel/air ratio $(\varphi>2)$. Figure 1 shows the uncertainty bars adopted from the literature $^{69}$ for atmospheric conditions. From our evaluation of the available data, illustrated in Figure 1, the uncertainty of syngas atmospheric laminar flame speeds can be assumed to be $10 \%$ for $\varphi<2,15 \%$ for $2<\varphi<3$, and $20 \%$ for $\varphi>3$. For higher pressures, we added $5 \%$ to the uncertainty. The results of this empirical rule for the data uncertainty evaluation

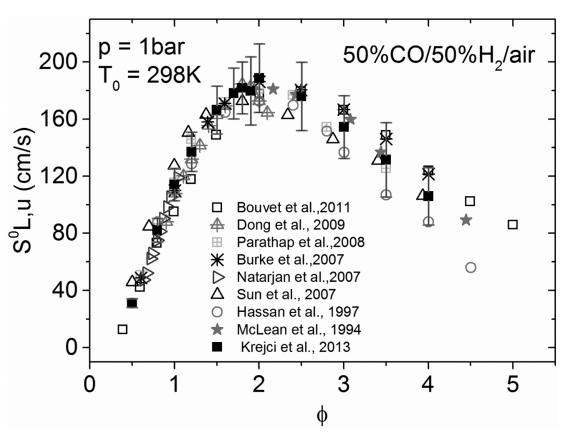

Figure 1. Comparison of literature experimental data for atmospheric 50:50 $\mathrm{H}_{2} / \mathrm{CO} /$ air laminar flame speed with the reported uncertainty bars. $^{69}$

Table 3. Evaluation of Uncertainty Intervals for the Selected Laminar Flames

\begin{tabular}{lcccccc}
\multicolumn{1}{c}{$\varphi$} & $p($ atm $)$ & $\begin{array}{c}\text { error } \\
(\%)\end{array}$ & $p($ atm $)$ & $\begin{array}{c}\text { error } \\
(\%)\end{array}$ & $p$ (atm) & $\begin{array}{c}\text { error } \\
(\%)\end{array}$ \\
$0.5-2$ & $1-5$ & 10 & $5-10$ & 15 & $>10$ & 20 \\
$2-3$ & $1-5$ & 15 & $5-10$ & 20 & $>10$ & 25 \\
$>3$ & $1-5$ & 20 & $5-10$ & 25 & $>10$ & 30 \\
\hline
\end{tabular}

are reported in Table 3. Laminar flame speed targets selected for analysis and their evaluated uncertainties can be found in Tables S2 and S4 of the Supporting Information. The complete dataset contains 167 QoI, 122 ignition delays, and 45 laminar flame speeds, presented in the Supporting Information.

4.3. Kinetic Model. The chemical reaction model assembled for the studied $\mathrm{H}_{2} / \mathrm{CO}$ system (6 elements, 17 species, and 73 reactions) is a submodel of the DLR $\mathrm{C}_{0}-\mathrm{C}_{2}$ reaction model, ${ }^{26}$ which is the base chemistry of the DLR reaction database for heavy hydrocarbon oxidation. Originally, this kinetic model was based on the $\mathrm{H} / \mathrm{O}, \mathrm{C}_{1}$, and $\mathrm{C}_{2}$ chemistry of the Leeds methane oxidation mechanism; ${ }^{25,120,141}$ it has been improved, modified, and extended ${ }^{26}$ on the basis of experimental data partially integrated into Table 1 . The complete list of the involved reactions and their kinetic parameters are reported in Table S5 of the Supporting Information. Most of the used kinetic data follow the recommendations by Baulch et al. $^{33}$ The modifications made in the present study, relative to prior evaluations, $^{33,120,141}$ are discussed next.

The chain initiation reaction

$$
\mathrm{H}_{2}+\mathrm{O}_{2} \rightarrow \mathrm{OH}+\mathrm{OH}
$$

was included in the model in addition to the step ${ }^{33}$

$$
\mathrm{H}+\mathrm{HO}_{2} \rightarrow \mathrm{H}_{2}+\mathrm{O}_{2}
$$

Three initiation reactions of $\mathrm{H}_{2}$ oxidation are usually discussed: ${ }^{142-146}$ reaction $\mathrm{R} 1$, reaction $\mathrm{R} 2$, and $\mathrm{H}_{2}+\mathrm{O}_{2} \rightarrow$ $\mathrm{O}+\mathrm{H}_{2} \mathrm{O}$. The values of Ripley et al. ${ }^{142}$ and Jachimovski et al. ${ }^{143}$ were obtained from the rate coefficient optimization of the experimental ignition delays. Michael et al. ${ }^{144}$ studied the total rate of initiation in a reflected shock tube. Through the fitting of the $\mathrm{O}$ radical concentration with the proposed reaction mechanism, it was concluded that reaction $\mathrm{R} 1$ is negligible and its rate constant was evaluated as 0. Filatov et al. ${ }^{145}$ investigated three possible modes (the concerted addition, the oxene insertion, and the hydrogen abstraction followed by hydrogen rebound) of reaction between dioxygen and dihydrogen molecules at the ground triplet state and excited singlet state of $\mathrm{O}_{2}$. With the performance of calculations 
at the $(14,10)$ CASSCF/6-31G** and MR-(S)DCI/cc-pVTZ levels of quantum theory, they found that the "rebound" mechanism is dominant among the three mechanisms. This "rebound" mechanism can be reduced to two sequences $\mathrm{H}_{2}+$ $\mathrm{O}_{2} \rightarrow \mathrm{H}+\mathrm{HO}_{2}, \mathrm{H}+\mathrm{HO}_{2} \rightarrow \mathrm{OH}+\mathrm{OH}$ and $\mathrm{H}_{2}+\mathrm{O}_{2} \rightarrow \mathrm{H}+$ $\mathrm{HO}_{2}, \mathrm{H}+\mathrm{HO}_{2} \rightarrow \mathrm{O}+\mathrm{H}_{2} \mathrm{O}$. Two other mechanisms, which lead to oxywater (the oxene insertion) and to $\mathrm{H}_{2} \mathrm{O}_{2}$ and $\mathrm{OH}+\mathrm{OH}$ (concerted addition), do not play any significant role in the oxidation reaction because their transition structures are highly energetic and are characterized by two imaginary frequencies. Karkach and Osherov ${ }^{146}$ investigated three chain initiating steps: $\mathrm{H}_{2}+\mathrm{O}_{2} \rightarrow 2 \mathrm{HO}, \mathrm{H}_{2}+\mathrm{O}_{2} \rightarrow \mathrm{H}+\mathrm{HO}_{2}$, and $\mathrm{H}_{2}+\mathrm{O}_{2} \rightarrow \mathrm{H}_{2} \mathrm{O}+\mathrm{O}$. These authors performed quantum $a b$ initio analysis of the transition structures on the triplet $\mathrm{H}_{2} \mathrm{O}_{2}$ potential energy surface responsible for the main chemical reactions and calculated the transition state theory rate constants for the most important bimolecular chemical channels. Karkach and Osherov ${ }^{146}$ have also confirmed that the reaction step R1 is relatively slow, but at the high pressure and high temperature conditions, it can influence the radical production process. Although reaction $\mathrm{R} 1$ cannot compete with its reverse (-R1) in initiation, we included this step in our model to have all conceivable initiation channels at the extreme operating conditions (rocket engines) and to ascertain the model completeness for future updates. The rate coefficient for reaction R1 was adopted from the work of Karkach and Osherov, ${ }^{146}$ with an uncertainty factor of 10. To support this selection, the comparison of the rate coefficient calculated by Karkach and Osherov ${ }^{146}$ for the reverse of reaction R2 to experimental data obtained in the study ${ }^{144}$ is shown on Figure 2 .

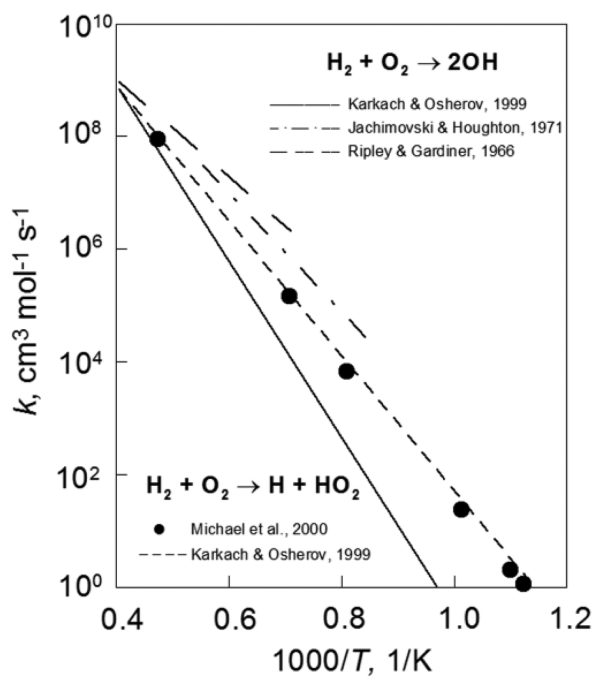

Figure 2. Arrhenius plot of rate coefficients for the $\mathrm{H}_{2}+\mathrm{O}_{2} \rightarrow \mathrm{OH}+$ $\mathrm{OH}^{142,143,146}$ and $\mathrm{H}_{2}+\mathrm{O}_{2} \rightarrow \mathrm{H}+\mathrm{HO}_{2}{ }^{144}$ reactions.

The three-molecular reaction

$$
\mathrm{H}+\mathrm{O}_{2}(+\mathrm{M}) \rightarrow \mathrm{HO}_{2}(+\mathrm{M})
$$

strongly influences combustion regimes of hydrogen and can shift the explosion limit behavior of $\mathrm{H}_{2} / \mathrm{O}_{2}$ mixtures. Hence, reaction $\mathrm{R} 3$ has been extensively studied experimentally and theoretically. ${ }^{66,82,147-152}$ Significant progress has been made to provide a detailed description of the rate coefficient dependence upon the temperature, pressure, and chemical nature of the bath gas $\mathrm{M}$. The rate coefficients obtained and recommended in the literature have very similar values, but $F_{\text {cent }}$ has a relatively large discrepancy in the data: $F_{\text {cent }}=0.5-$ 0.72 for $\mathrm{M}=\mathrm{Ar}$ and $\mathrm{N}_{2}$, and $F_{\text {cent }}=0.5-0.8$ for $\mathrm{M}=$ $\mathrm{H}_{2} \mathrm{O} .{ }^{148,151,152}$ The rate coefficient of Troe ${ }^{152}$ was incorporated in the model for the high-pressure limit. The low-pressure-limit rate coefficients for $\mathrm{M}=\mathrm{He}, \mathrm{O}_{2}$, and $\mathrm{N}_{2}$ measured by Michael and co-workers ${ }^{150}$ and for $\mathrm{M}=\mathrm{Ar}$ and $\mathrm{H}_{2} \mathrm{O}$ measured by Bates et al. ${ }^{147}$ were adopted. The study and recommendations of Fernandes et al. ${ }^{148}$ performed for the falloff behavior were considered: $F_{\text {cent }}=0.5$ for $\mathrm{M}=\mathrm{He}, \mathrm{Ar}, \mathrm{O}_{2}$, and $\mathrm{N}_{2}$, and $F_{\text {cent }}=$ 0.6 for $\mathrm{M}=\mathrm{H}_{2} \mathrm{O}$.

The rate coefficients of hydrogen recombination with different third bodies

$$
\mathrm{H}+\mathrm{H}+\mathrm{M} \rightarrow \mathrm{H}_{2}+\mathrm{M}
$$

were updated on the basis of analysis performed in the work. ${ }^{149}$ We note that there are no reliable experimental data for this reaction, and its reaction rate value accepted in the literature, in different models and reviews, follows from ref 153. For $\mathrm{M}=\mathrm{Ar}$, the rate value from the study ${ }^{33}$ and for $\mathrm{M}=\mathrm{H}, \mathrm{H}_{2}, \mathrm{~N}_{2}$, and $\mathrm{H}_{2} \mathrm{O}$ from the investigation ${ }^{153}$ were used in the present model.

The atom transfer reaction

$$
\mathrm{CO}+\mathrm{O}_{2} \rightarrow \mathrm{CO}_{2}+\mathrm{O}
$$

has been studied by different research groups and is welldocumented. ${ }^{50,154-158}$ Selected experimental data are shown in Figure 3. The correlation recommended by Tsang and

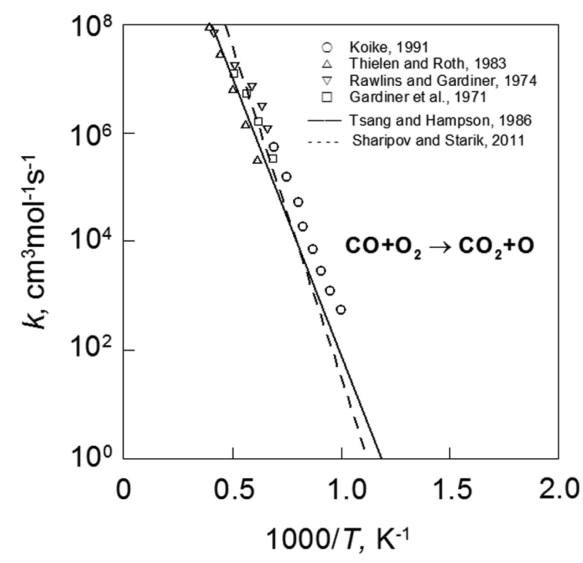

Figure 3. Temperature dependence of the rate coefficient for reaction R5 measured by different researchers (symbols) and estimated by Tsang and Hampson ${ }^{158}$ and Sharipov and Starik ${ }^{156}$ (lines).

Hampson ${ }^{158}$ and quantum chemical calculations of Sharipov and Starik ${ }^{156}$ give good agreement with the experimental data. The rate coefficient adopted in the present work is based on the recommendation of Tsang and Hampson, ${ }^{158}$ with an uncertainty factor of 5 .

The bimolecular reaction

$$
\mathrm{H}+\mathrm{HCO} \rightarrow \mathrm{H}_{2}+\mathrm{CO}
$$

has a chain-terminating character. The formation of $\mathrm{H}_{2}$ and $\mathrm{CO}$ at all temperatures occurs predominantly by direct abstraction studied by Christoffel and Bowman. ${ }^{159}$ The recommendation of Baulch et al., ${ }^{33}$ adopted in the present study, treats the rate coefficient of this reaction as nearly independent of the temperature between 298 and $2500 \mathrm{~K}$, with an average value of $9.0 \times 10^{13} \mathrm{~cm}^{3} \mathrm{~mol}^{-1} \mathrm{~s}^{-1}$ and an uncertainty factor of 2. These data agree with the relatively new experiments of 
Friedrichs et al. ${ }^{160}$ and the classical trajectory study of Troe and Ushakov. ${ }^{161}$

The well-studied reaction

$$
\mathrm{HO}+\mathrm{CO} \rightarrow \mathrm{H}+\mathrm{CO}_{2}
$$

is important in combustion chemistry because it is the main pathway in the conversion of $\mathrm{CO}$ to $\mathrm{CO}_{2}$, with a major energy release derived in the oxidation of hydrocarbons. The reaction rate coefficient is essentially flat at low temperatures but increases quickly at $T>500 \mathrm{~K}^{33}$ This behavior is attributed to the complex mechanism of the reaction that proceeds via the formation of a vibrationally excited $\mathrm{HOCO}$ intermediate, HOCO*, which can decompose to form $\mathrm{H}$ and $\mathrm{CO}_{2}$ or undergo collisional stabilization. Joshi and Wang ${ }^{162}$ showed that the formation of the $\mathrm{HOCO}$ adduct leads to an increase in the rate coefficient with pressure, but most available syngas mechanisms do not include HOCO. Recently, the inclusion of the HOCO reaction subset was investigated by Nilsson and Konnov. ${ }^{88}$ It was shown that the HOCO reaction subset does not alter the model predictions of laminar burning velocities, ignition delay times, or oxidation and can be needed mostly at the high pressures and low temperatures. Therefore, HOCO was not included in the present mechanism, and reaction $\mathrm{R} 8$ was treated as pressure independent. Its rate coefficient was based on the recommendation of Baulch et al., ${ }^{33}$ which is in good agreement with recent experimental investigations. ${ }^{162,163}$ The uncertainty factor of this rate coefficient was estimated to be 1.26 .

High-temperature oxidation of hydrocarbons is known to be sensitive to reaction

$$
\mathrm{HCO}+\mathrm{O}_{2} \rightarrow \mathrm{CO}+\mathrm{HO}_{2}
$$

Other channels of this reaction that form $\mathrm{CO}_{2}+\mathrm{OH}$ or $\mathrm{HCO}_{3}$ are of little importance under the conditions relevant to combustion. ${ }^{33}$ Recent shock-tube measurements of Colberg and Friedrichs ${ }^{164}$ in the temperature range of 739-1108 $\mathrm{K}$ and Fassheber $^{165}$ at temperatures of $1285-1760 \mathrm{~K}$ allow for a reasonable fit of the overall temperature dependence of the available data in the form of an extended Arrhenius expression over the temperature range of 295-1705 K, $k_{\mathrm{R} 8}=6.92 \times$ $10^{6} \mathrm{~T}^{1.90} \mathrm{e}^{690 / T} \mathrm{~cm}^{3} \mathrm{~mol}^{-1} \mathrm{~s}^{-1}$, as shown in Figure 4. This expression

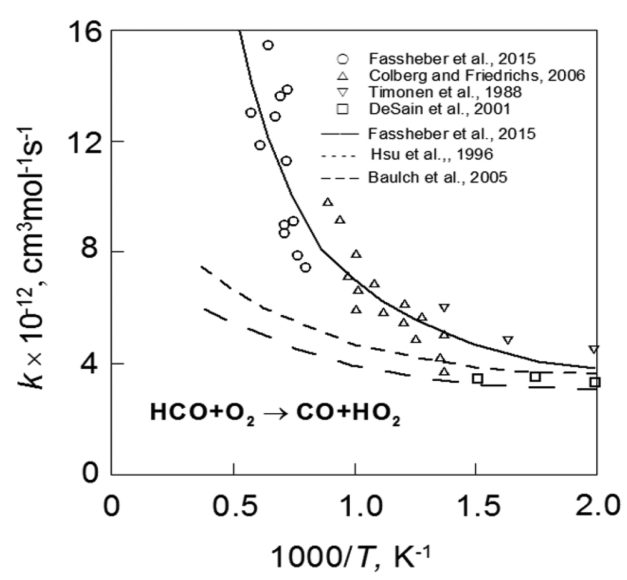

Figure 4. Arrhenius plot of the measured rate coefficient $k_{\mathrm{R} 8}$ from Colberg and Friedrichs, ${ }^{164}$ Fassheber et al., ${ }^{165}$ DeSain et al., ${ }^{166}$ Timonen et al., ${ }^{167}$ the theoretical study of $\mathrm{Hsu}$ et al., ${ }^{168}$ and recommendations of Fassheber et al. ${ }^{165}$ and Baulch et al. ${ }^{33}$ was accepted in the present work. The uncertainty of this rate constant is close to a factor of 2.5.

Although there is much interest in reaction

$$
\mathrm{CO}+\mathrm{HO}_{2} \rightarrow \mathrm{CO}_{2}+\mathrm{OH}
$$

because of its influence on syngas combustion at high pressure and temperature, large discrepancies exist among literature rate values for gas turbine operating conditions. ${ }^{84,101,158,169,170}$ Existing experimental studies of the rate coefficient of reaction R9 have been performed mostly at low temperatures, below $500 \mathrm{~K}$. At higher temperatures, the rate coefficient has been evaluated either indirectly or inferred from kinetic measurements when reaction R9 is of secondary importance. ${ }^{170}$ In the previous revision of the present model, the reaction rate coefficient was adopted from Tsang and Hampson. ${ }^{158}$ It was recently pointed out that the rate should be revised to a lower value. For instance, such a trend was obtained by Mueller et al. ${ }^{84}$ in the development of a detailed kinetic mechanism on the basis of experimentally measured species profiles over wide ranges of pressure $(0.5-14.0 \mathrm{~atm})$ and temperature $(750-1100 \mathrm{~K})$. The estimations of Mittal et al., ${ }^{169}$ deduced from ignition delay measurements and modeling with a complex kinetic model, also suggest a decrease in the rate coefficient by a factor of 10 from that of Baulch et al. ${ }^{33} \mathrm{~A}$ further decrease in the rate coefficient value of reaction R9 was suggested in $a b$ initio calculations performed at pressures up to $40 \mathrm{~atm}$ and temperatures of $300-2500 \mathrm{~K}$ by Sun et al. ${ }^{101}$ and for pressures up to $500 \mathrm{~atm}$ and temperatures of $300-2500 \mathrm{~K}$ by You et al. ${ }^{170}$ The value of the rate coefficient adopted in our model for reaction R9 follows the calculations of Sun et al., ${ }^{101}$ with an uncertainty factor of 2.

The hydrogen atom in $\mathrm{HCO}$ is weakly bonded and is relatively easily lost in direct unimolecular decomposition under combustion conditions

$$
\mathrm{HCO}+\mathrm{M} \rightarrow \mathrm{H}+\mathrm{CO}+\mathrm{M}
$$

The direct measurements of the rate coefficient for this reaction at moderately low temperatures were performed by Timonen et al. ${ }^{171}\left(\mathrm{M}=\mathrm{He}, \mathrm{N}_{2}\right.$, and $\left.\mathrm{Ar}\right)$ and Krasnoperov et al. ${ }^{172}$ $(\mathrm{M}=\mathrm{He})$. The data of Friedrichs et al. ${ }^{160}$ bridge the temperature gap between the direct data of Timonen et al. and Krasnoperov et al. and the indirect high-temperature measurements of Cribb et al., ${ }^{173}$ as shown in Figure 5. In the study of Li

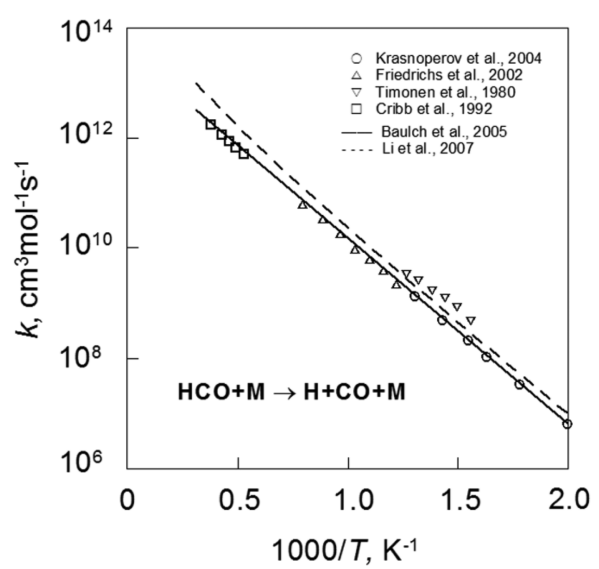

Figure 5. Rate coefficient of reaction $\mathrm{HCO}+\mathrm{M} \rightarrow \mathrm{H}+\mathrm{CO}+\mathrm{M}$. Symbols are experimental data. Lines are the recommendations of Baulch et al. ${ }^{33}$ and Li et al. ${ }^{76}$ 
et al., ${ }^{76}$ the weighted least squares fit of literature results for reaction R10 yielded $k_{\mathrm{R} 10}=4.75 \times 10^{11} T^{0.66} \mathrm{e}^{-7485 / T} \mathrm{~cm}^{3} \mathrm{~mol}^{-1} \mathrm{~s}^{-1}$, which predicts values within uncertainties of both prior and new measurements. ${ }^{160,166,167,172}$ It must be pointed out that these correlations were obtained by fitting low-pressure-limit data. Nevertheless, significant deviations from the low-pressure limit can occur only at high pressures ${ }^{172}$ that are beyond the scope of practical combustion processes. ${ }^{171}$ Therefore, reaction R10 may be regarded as being in the low-pressure limit for most combustion applications. The rate constant adopted in the present work was based on the recommendations of $\mathrm{Li}$ et al. ${ }^{76}$

Destruction of $\mathrm{CO}$ by $\mathrm{O}$ atoms in reaction

$$
\mathrm{CO}+\mathrm{O}(+\mathrm{M}) \rightarrow \mathrm{CO}_{2}(+\mathrm{M})
$$

is important only in the dry combustion of $\mathrm{CO}$ because the destruction of $\mathrm{CO}$ by $\mathrm{OH}$ radicals is much faster otherwise. Therefore, a major problem in measuring the rate coefficient of reaction $\mathrm{R} 11$ is that any $\mathrm{H}_{2} \mathrm{O}$ impurity leads to $\mathrm{OH}$ formation that, in turn, accelerates $\mathrm{CO}$ destruction significantly. The rate coefficient exhibits pressure dependence at pressures in excess of $1 \mathrm{~atm} .{ }^{158}$ Available data show that the activation energy in the low-pressure limit seems to be positive at low temperatures but negative at high temperatures, switching at about $1000 \mathrm{~K}^{174}$ In most combustion models, ${ }^{10,63,76,102}$ the combination of the low-pressure rate coefficient from Westmoreland et al. ${ }^{174}$ and the high-pressure rate coefficient from Troe, ${ }^{175}$ slightly modified by Mueller et al., ${ }^{84}$ is used. The rate coefficient adopted in the present work was based on this latter recommendation, with the uncertainty factor of 2 . Another recommendation is based on the low-pressure rate constant of Tsang and Hampson. ${ }^{158}$ Nilsson and Konnov ${ }^{88}$ use the recently calculated high-pressure rate coefficient of Jasper and Dawes, ${ }^{176}$ which is $7-35$ times larger than the value used in many combustion kinetic models.

The present model was extended with the $\mathrm{OH}^{*}$ reaction submechanism, taken from Kathrotia et al., ${ }^{177}$ to reproduce the ignition delay times recorded in shock tubes by the $\mathrm{OH}^{*}$ chemiluminescent measurements.

The model parameters, the selected nominal reaction rate coefficients, and the uncertainty ranges assigned to multipliers $\lambda$ are listed in Table S6 of the Supporting Information. The uncertainties in the active parameters, represented by the lower and upper bounds of $\lambda$, were assumed equal to those proposed in literature sources or evaluated from a statistical treatment of the literature data.

A preferred key (or PrIMe ID) was prescribed to each structural element in the reaction model. In this way, each structural element has a "pointer" to the referenced information and/or file. Such a constructed set of files defines the reaction model, $C(x)$, in PrIMe. All of the experimental and model data were documented in the PrIMe data warehouse. Selected for analysis, experimental QoI are described in the dataAttribute files of the PrIMe data collection. ${ }^{16}$ These QoI together with the corresponding model $M_{e}(x)$ and the experimental and parameter bounds form a dataset. We will designate the present dataset as DLR-SynG. The complete model and experimental data are available in the PrIMe data warehouse. ${ }^{16}$

\section{RESULTS AND DISCUSSION}

The ignition delay times and laminar flame speeds were modeled with numerical tools of $\operatorname{PrIMe}^{16}$ and numerical packages CHEMKIN II ${ }^{178}$ and Chemical Workbench. ${ }^{179}$ The ignition delay time was computationally defined by the peak in the $\mathrm{OH}$ or $\mathrm{OH}^{*}$ concentration, temperature, or pressure. The thermal diffusion model was applied for calculation of the one-dimensional freely propagating laminar premixed flame using CHEMKIN II with over 1000 grid points for each condition.

5.1. Consistency Analysis. We began the analysis by employing eq 3 with the initial dataset, DLR-SynG 0, which included all 167 QoI (122 ignition delays and 45 laminar flame speeds) and 55 active parameters (Tables S3-S5 of the Supporting Information). The results indicated a massive inconsistency. Eight QoI, those listed in Table 4, were found to

\section{Table 4. Eight Self-Inconsistent QoI}

\begin{tabular}{cccccc}
$T_{5}(\mathrm{~K})$ & $p_{5}(\mathrm{~atm})$ & $\phi$ & $\begin{array}{c}\text { target PrIMe } \\
\text { ID }\end{array}$ & $\begin{array}{c}\text { estimated uncertainty } \\
(\%)\end{array}$ & reference \\
1263 & 1.1 & 0.5 & $\mathrm{a} 00000309$ & 30 & 61 \\
1695 & 1.6 & 0.5 & $\mathrm{a} 00000352$ & 30 & 69 \\
2004 & 1.6 & 0.5 & $\mathrm{a} 00000355$ & 25 & 69 \\
1975 & 1.6 & 0.5 & $\mathrm{a} 00000358$ & 25 & 69 \\
1436 & 1.6 & 0.5 & $\mathrm{a} 00000359$ & 25 & 69 \\
1027 & 1.6 & 0.5 & $\mathrm{a} 00000360$ & 35 & 69 \\
1883 & 1.6 & 0.5 & $\mathrm{a} 00000503$ & 30 & 80 \\
1008 & 1.6 & 0.5 & $\mathrm{a} 00000504$ & 50 & 80 \\
\hline
\end{tabular}

be self-inconsistent. These were the ignition delay times that were not able to be reproduced within their respective uncertainty bounds by the model employing rate coefficients within their respective uncertainty bounds, $H$. These eight selfinconsistent QoI were removed from the initially constructed dataset, thus forming what we refer to as the DLR-SynG 1 dataset. The latter, however, still remained an inconsistent dataset.

To continue with the analysis, we employed a newly developed method of computing the vector consistency measure (VCM), similar to eq 3 but with original constraints augmented with individual relaxations $\gamma_{e}$ for each bound. ${ }^{180}$ The VCM method determines the minimal bound changes, each bound by its own extent, that result in dataset consistency. Its application to DLR-SynG 1 identified such a dataset-consistency point by changing 30 ignition delay times and 7 laminar flame speeds, shown in Tables 5 and 6, respectively. We emphasize that the VCM-identified feasible parameter set is a single point in $H$. Because this point possesses some optimal attributes, we compare the model predictions obtained with this set of parameters, $M\left(x_{\mathrm{VCM}}\right)$, to the optimization results in section 5.3.

To proceed with further features of the B2BDC framework, we created a new dataset by removing the $37 \mathrm{QoI}$ identified by VCM, thus forming the DLR-SynG 2 dataset contacting 122 QoI. This latter dataset is consistent, meaning that all of its 122 QoI are consistent with each other and with the 55 active parameters.

5.2. Posterior Information. The reader may recall that we started the analysis by creating $H$, which designates a subset of parameters that represents the prior knowledge on their uncertainties. The shape of $H$ can be either rectangular, implying independence of individual parameter uncertainties, ${ }^{9,15}$ or truncated by planes or surfaces imposing known correlations among parameters. Typical examples of such $a$ priori correlations are those between pre-exponential factors and activation energies of rate coefficients ${ }^{11,127}$ or rate constant ratios. ${ }^{181}$ While there are no limitations to employing such additional information within the B2BDC framework, the 
Table 5. Bound Changes of the Ignition QoI Suggested by VCM

\begin{tabular}{|c|c|c|c|c|c|c|c|}
\hline$T_{5}(\mathrm{~K})$ & $p_{5}(\mathrm{~atm})$ & $\phi$ & target PrIMe ID & estimated uncertainty (\%) & reference & lower bound change (\%) & upper bound change (\%) \\
\hline 900 & 0.6 & 0.5 & a00000110 & 50 & 61 & -14.84 & \\
\hline 936 & 1.2 & 0.5 & a00000113 & 40 & 61 & & 13.00 \\
\hline 1015 & 1.1 & 0.5 & a00000189 & 30 & 61 & & 0.92 \\
\hline 1183 & 1.1 & 0.5 & a00000190 & 30 & 61 & & 10.14 \\
\hline 929 & 2.6 & 0.5 & a00000191 & 50 & 61 & & 431.95 \\
\hline 1132 & 16.2 & 0.5 & a00000228 & 35 & 58 & -12.78 & \\
\hline 1051 & 15.3 & 0.5 & a00000236 & 30 & 58 & -2.56 & \\
\hline 1097 & 15.6 & 0.5 & a00000237 & 35 & 58 & -13.48 & \\
\hline 1054 & 15.6 & 0.5 & a00000241 & 30 & 58 & & 86.11 \\
\hline 1057 & 1.1 & 0.5 & a00000308 & 30 & 61 & & 1.46 \\
\hline 977 & 2.3 & 0.5 & a00000310 & 40 & 61 & & 187.12 \\
\hline 1149 & 2 & 0.5 & a00000311 & 30 & 61 & & 28.59 \\
\hline 1304 & 1.7 & 0.5 & a00000312 & 30 & 61 & & 48.63 \\
\hline 943 & 22.3 & 0.5 & a00000316 & 35 & 91 & & 175.15 \\
\hline 1182 & 12 & 0.5 & a00000335 & 25 & 69 & & 11.94 \\
\hline 1351 & 1.6 & 0.5 & a00000353 & 30 & 69 & & 17.76 \\
\hline 980 & 1.6 & 0.5 & a00000354 & 40 & 69 & & 44.21 \\
\hline 1273 & 1.6 & 0.5 & a00000356 & 25 & 69 & & 6.02 \\
\hline 992 & 1.6 & 0.5 & a00000357 & 35 & 69 & & 28.49 \\
\hline 1146 & 1.6 & 0.5 & a00000490 & 30 & 80 & -4.55 & \\
\hline 1397 & 12.5 & 0.5 & a00000498 & 30 & 80 & -16.77 & \\
\hline 1284 & 12.5 & 0.5 & a00000499 & 30 & 80 & -1.25 & \\
\hline 1100 & 12.5 & 0.5 & a00000500 & 30 & 80 & & 51.79 \\
\hline 1360 & 12.5 & 0.5 & a00000505 & 30 & 80 & & 51.07 \\
\hline 1291 & 32 & 0.5 & a00000507 & 30 & 80 & & 14.50 \\
\hline 981 & 1.2 & 1.0 & a00000491 & 20 & 108 & -79.93 & \\
\hline 1065 & 1.3 & 1.0 & a00000492 & 20 & 108 & -6.40 & \\
\hline 975 & 1.7 & 1.0 & a00000495 & 20 & 108 & -34.47 & \\
\hline 999 & 1.8 & 1.0 & a00000496 & 20 & 108 & -44.16 & \\
\hline 1048 & 1.7 & 1.0 & a00000497 & 20 & 108 & -10.55 & \\
\hline
\end{tabular}

Table 6. Bound Changes of the Laminar Flame Speed QoI Suggested by VCM

\begin{tabular}{|c|c|c|c|c|c|c|c|c|}
\hline$T_{0}(\mathrm{~K})$ & $p(\mathrm{~atm})$ & mixture & $\phi$ & $\begin{array}{l}\text { target PrIMe } \\
\text { ID }\end{array}$ & $\begin{array}{l}\text { estimated uncertainty } \\
(\%)\end{array}$ & reference & $\begin{array}{l}\text { lower bound change } \\
(\%)\end{array}$ & $\begin{array}{l}\text { upper bound change } \\
(\%)\end{array}$ \\
\hline 300 & 1.0 & $50 / 50 \% \mathrm{CO} / \mathrm{H}_{2} /$ air & 0.8 & $\mathrm{a} 00000128$ & 10 & 101 & -0.73 & \\
\hline 300 & 1.0 & $50 / 50 \% \mathrm{CO} / \mathrm{H}_{2} / \mathrm{air}$ & 1.2 & a00000129 & 10 & 101 & -0.30 & \\
\hline 300 & 1.0 & $95 / 5 \% \mathrm{CO} / \mathrm{H}_{2} /$ air & 1 & a00000260 & 10 & 101 & & 2.43 \\
\hline 300 & 0.5 & $95 / 5 \% \mathrm{CO} / \mathrm{H}_{2} /$ air & 1 & a00000269 & 10 & 56 & & 4.74 \\
\hline 300 & 1.0 & $95 / 5 \% \mathrm{CO} / \mathrm{H}_{2} /$ air & 0.6 & a00000271 & 10 & 56 & -6.75 & \\
\hline 600 & 15.0 & $50 / 50 \% \mathrm{CO} / \mathrm{H}_{2} / \mathrm{He}$ & 0.6 & $\mathrm{x} 00000471$ & 20 & 85 & -6.18 & \\
\hline 373 & 1.0 & $\begin{array}{c}50 \% \mathrm{H}_{2}-50 \% \mathrm{CO} / \mathrm{air}, \\
\mathrm{H}_{2} \mathrm{O}=0.15\end{array}$ & 1.2 & a00000534 & 10 & 114 & & 5.34 \\
\hline
\end{tabular}

present results indicate that the main point at issue is the quality of the experimental data and not necessarily that of parameters. This is demonstrated by examining sensitivities of the consistency measure of the DLR-SynG 2 dataset with respect to the uncertainty bounds of parameters and QoI, displayed in Figure 6. Inspection of these results shows a significantly larger impact (i.e., Isensitivity $\times$ uncertaintyl) on the degree of consistency from the experimental uncertainty compared to that of the parameter uncertainty. In light of this, we employed a rectangular $H$ in the present work, leaving the a priori parameter correlations to future refinements.

While $H$ designates prior information, feasible set $F$ summarizes posterior information: all parameter value combinations that satisfy their own bounds and also the QoI bounds. The size and shape of $F$ compared to those of $H$ represent information gained as a result of the B2BDC analysis. Projection of $F$ on each $x$ yields the posterior range of the parameter uncertainty. ${ }^{15}$ Those that changed are reported in Table 7. For the rest of the parameters, the posterior ranges were the same as the prior ones, indicating that the experimental data included in the present analysis did not aid in narrowing down the uncertainty ranges of these parameters individually. However, such an outcome does not necessarily imply no information gain for a given parameter; while the extreme parameter values (bounds) may not change, the feasible set may and usually does eliminate some combinations of these parameters with others, which is addressed next.

Two-dimensional projections of $F$ on pairs of $x$ reveal their mutual correlation. Examples of possible outcomes are shown in Figure 7. The top left panel in Figure 7 demonstrates the absence of correlation; any pair of values of the rate coefficients of reactions $\mathrm{HCO}+\mathrm{O} \rightarrow \mathrm{CO}+\mathrm{OH}$ and $\mathrm{HCCO}+\mathrm{O}_{2} \rightarrow \mathrm{CO}_{2}$ $+\mathrm{CO}+\mathrm{H}$ within their respective $\left(\lambda_{\min }, \lambda_{\max }\right)$ bounds is feasible. The top right panel also shows a case of no correlation, but 

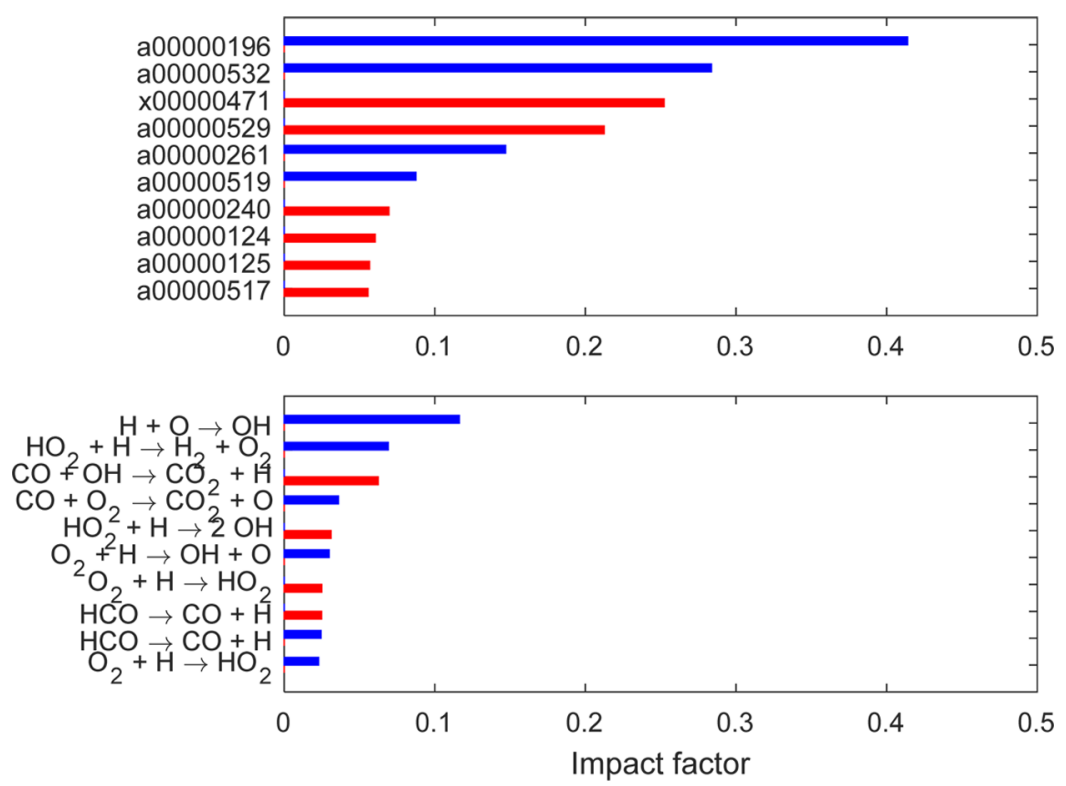

Figure 6. Impact factors (Isensitivity $\times$ uncertaintyl) of DLR-SynG 2 consistency measure with respect to upper (red) and lower (blue) uncertainty bounds of QoI (top) and model parameters (bottom). Only the top 10 are shown for each case.

Table 7. Active Parameters with a Decrease in Uncertainty Ranges $^{a}$

\begin{tabular}{lccccc} 
& \multicolumn{2}{c}{$\lambda$ prior bounds } & & \multicolumn{2}{c}{$\begin{array}{c}\lambda \text { posteri- } \\
\text { or bounds }\end{array}$} \\
\cline { 2 - 3 } \multicolumn{1}{c}{ reaction } & lower & upper & & lower & upper \\
$\mathrm{HO}_{2}+\mathrm{H} \rightarrow \mathrm{H}_{2}+\mathrm{O}_{2}$ & 0.50 & 2.00 & & 0.56 & 2.00 \\
$\mathrm{CO}+\mathrm{OH} \rightarrow \mathrm{CO}_{2}+\mathrm{H}$ & 0.80 & 1.26 & & 0.80 & 1.08 \\
$\mathrm{CO}+\mathrm{O}+\mathrm{M}) \rightarrow \mathrm{CO}_{2}(+\mathrm{M})$ & 0.50 & 2.00 & & 0.50 & 1.97 \\
$\mathrm{H}+\mathrm{O}+\mathrm{M} \rightarrow \mathrm{OH}+\mathrm{M}$ & 0.20 & 5.00 & & 0.96 & 5.00 \\
$\mathrm{H}_{2}+\mathrm{O} \rightarrow \mathrm{OH}+\mathrm{H}$ & 0.63 & 1.58 & & 0.81 & 1.58 \\
$\mathrm{HO}_{2}+\mathrm{OH} \rightarrow \mathrm{H}_{2} \mathrm{O}+\mathrm{O}_{2}$ & 0.32 & 3.16 & & 0.39 & 3.16 \\
$\mathrm{H}_{2}+\mathrm{OH} \rightarrow \mathrm{H}_{2} \mathrm{O}+\mathrm{H}$ & 0.65 & 1.63 & & 0.65 & 1.52 \\
$\mathrm{O}_{2}+\mathrm{H} \rightarrow \mathrm{OH}+\mathrm{O}$ & 0.80 & 1.26 & & 0.90 & 1.26
\end{tabular}

${ }^{a}$ Bounds that changed are shown in italic.

now while any of the $\left(\lambda_{\min }, \lambda_{\text {max }}\right)$ values for reaction $\mathrm{CH}+\mathrm{O} \rightarrow$ $\mathrm{CO}+\mathrm{H}$ is feasible, for reaction $\mathrm{CO}+\mathrm{OH} \rightarrow \mathrm{CO}_{2}+\mathrm{H}$, only $\lambda$ values within a narrower range, about $(0.80,0.86)$, are feasible. The bottom left panel shows a positive correlation, with higher values of $\lambda\left(\mathrm{O}_{2}+\mathrm{H} \rightarrow \mathrm{OH}+\mathrm{O}\right)$ feasible only with higher values of $\lambda\left(\mathrm{O}_{2}+\mathrm{H} \rightarrow \mathrm{HO}_{2}\right)$ and vice versa, and the bottom right panel shows a negative correlation and is substantially shifted from the initial recommendations, represented by the central point, $\left(\begin{array}{ll}0 & 0\end{array}\right)$. A collection of all two-dimensional projections informs the structure of the feasible set, $F$. One can also explore three- or four-dimensional correlation plots.

Projections of $F$ on parameter-QoI pairs depict correlations of the parameter and QoI uncertainties. Several such examples are presented in Figure 8. Furthermore, the B2BDC framework also allows one to examine correlations among QoI uncertainties. These examples are shown in Figure 9. It is pertinent to note that the initially selected QoI were assumed uncorrelated. The correlations exposed in Figure 9 have their origin in the constraints imposed in the model-data system, the DLR-SynG 2 dataset. For instance, the bottom left panel of Figure 9 indicates that predictions for the flame speed of QoI a00000535 and ignition delay time of QoI a00000318 can have only values represented by the blue region. The latter originates from the kinetic model being constrained to reproduce the rest of the experimental observations within their respective ranges of uncertainties.

5.3. Parameter Optimization. While the primary focus of the B2BDC framework is on prediction over the feasible set, it also supports parameter optimization. ${ }^{130}$ Four sets of optimized model parameters were investigated and intercompared in the present study. The first approach is LS-H, a (weighted) leastsquared fit constraining parameter values to their initially assessed uncertainty ranges, $H$. This is now a common approach. ${ }^{2,5,9,12,63,127,129}$ B2BDC supports two more refined methods of optimization, ${ }^{130}$ LS-F and $1 \mathrm{~N}-\mathrm{F}$, where the objective is minimized with $x$ being constrained to the feasible set $F$. The three problems are easily expressed as mathematical optimizations. The LS methods minimize the familiar sum of weighted least squared deviations, with weights $w_{e}$, between the surrogate model prediction and the reported measured value, $y_{e}$. The difference lies in where the search takes place: LS-H considers all of $H$, while LS-F restricts the search to $F$.

$$
\begin{aligned}
& \text { LS-H: } \min _{x \in H} \sum_{e} w_{e}\left[M_{e}(x)-y_{e}\right]^{2} \\
& \text { LS-F: } \min _{x \in F} \sum_{e} w_{e}\left[M_{e}(x)-y_{e}\right]^{2}
\end{aligned}
$$

In contrast, the $1 \mathrm{~N}-\mathrm{F}$ problem treats the nominal parameter vector, the starting set of parameter values $\left(x_{0}=0\right)$, as "preferred". As seen in section 5.1, this parameter set lies outside the feasible region $F$. The goal of the $1 \mathrm{~N}-\mathrm{F}$ method is to find with fewest number of changes to $x_{0}$, a parameter vector that is feasible. Mathematically, the one norm, \|\|$_{1}$, is a wellknown approximation to enforce such sparsity, ${ }^{22}$ i.e.

$$
\text { 1N-F: } \min _{x \in F}\left\|x-x_{0}\right\|_{1}
$$

The LS-F and 1N-F optimizations were performed with the final dataset, DLR-SynG 2, because the two methods are designed to work with an existing feasible set. Finally, the fourth set of parameters that we examined is the one 

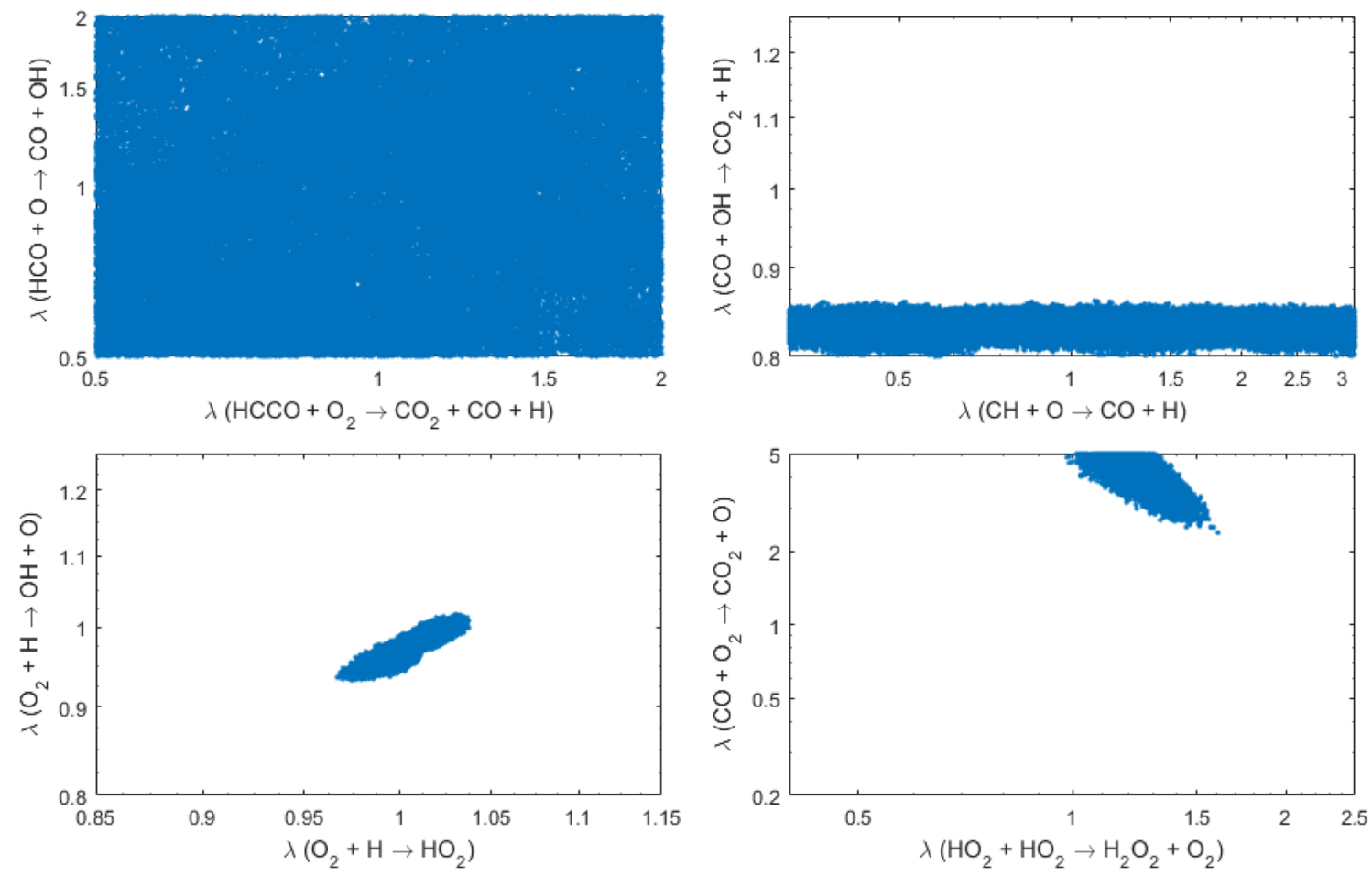

Figure 7. Two-dimensional projections of feasible set $F$ on pairs of $x$. The axes are rate-coefficient multipliers, $\lambda$, of the indicated reactions. Their ranges represent the uncertainty bounds.
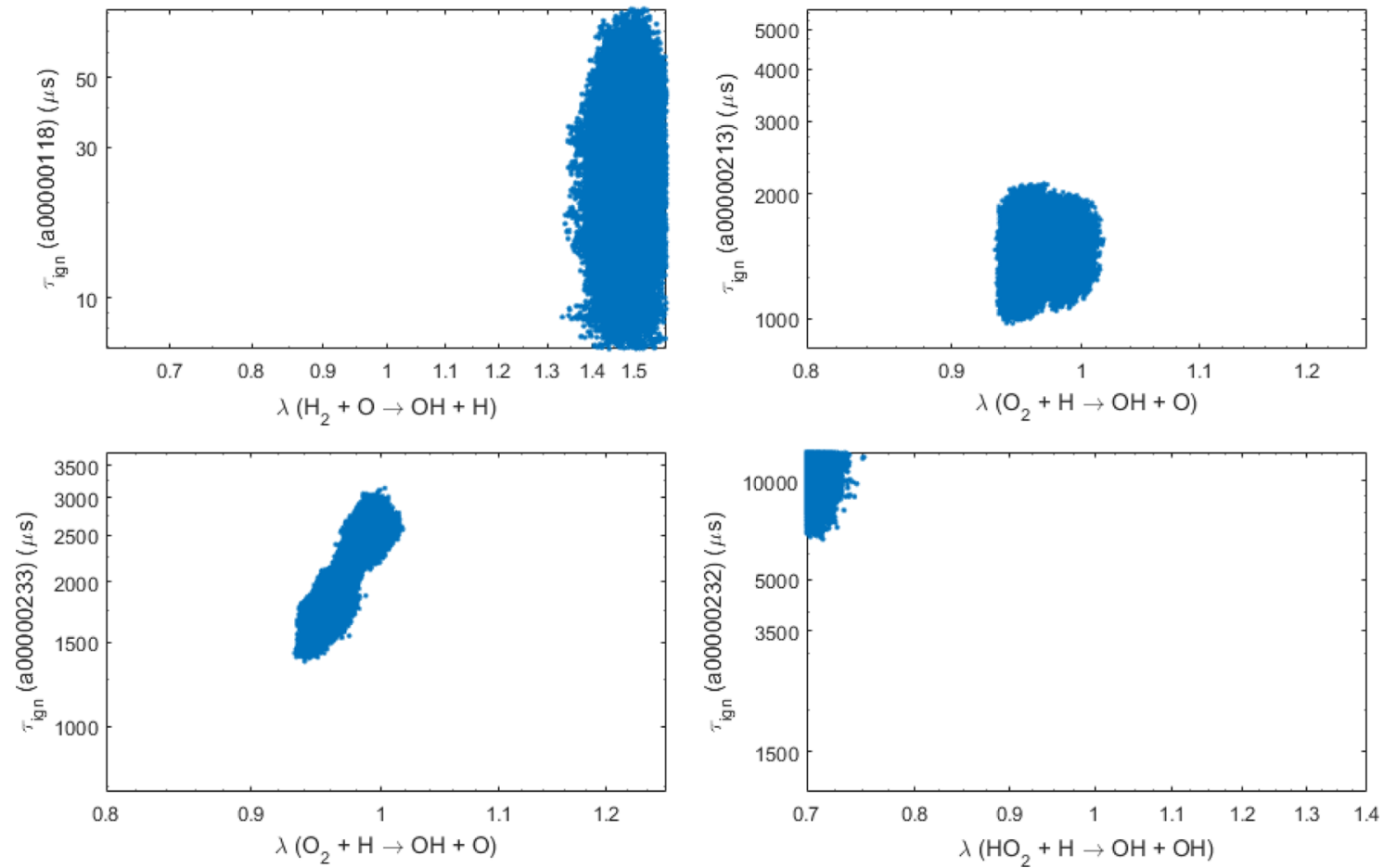

Figure 8. Two-dimensional projections of feasible set $F$ on parameter-QoI pairs. The horizontal axes are rate-coefficient multipliers, $\lambda$, of the indicated reactions, and the vertical axes are QoI values. Their ranges represent the uncertainty bounds.

corresponding to the single consistent point of the DLR-SynG 1 dataset, resulting from the VCM optimization. ${ }^{180}$

The average deviations of the optimized model predictions from the experimental observations are depicted in Figure 10. The deviations for all individual experiments are given in Figure S1 of the Supporting Information. Some of the individual comparisons are shown in Figures 11-17, with the inclusion of the most recent literature model. ${ }^{12}$ Experimental targets of the DLR-SynG dataset in these figures are designated by a star. The eight self-inconsistent QoI (excluded from the DLR-SynG 0; Table 4) are colored red, and those excluded from DLR-SynG 1 (listed in Tables 5 and 6) are colored green. 

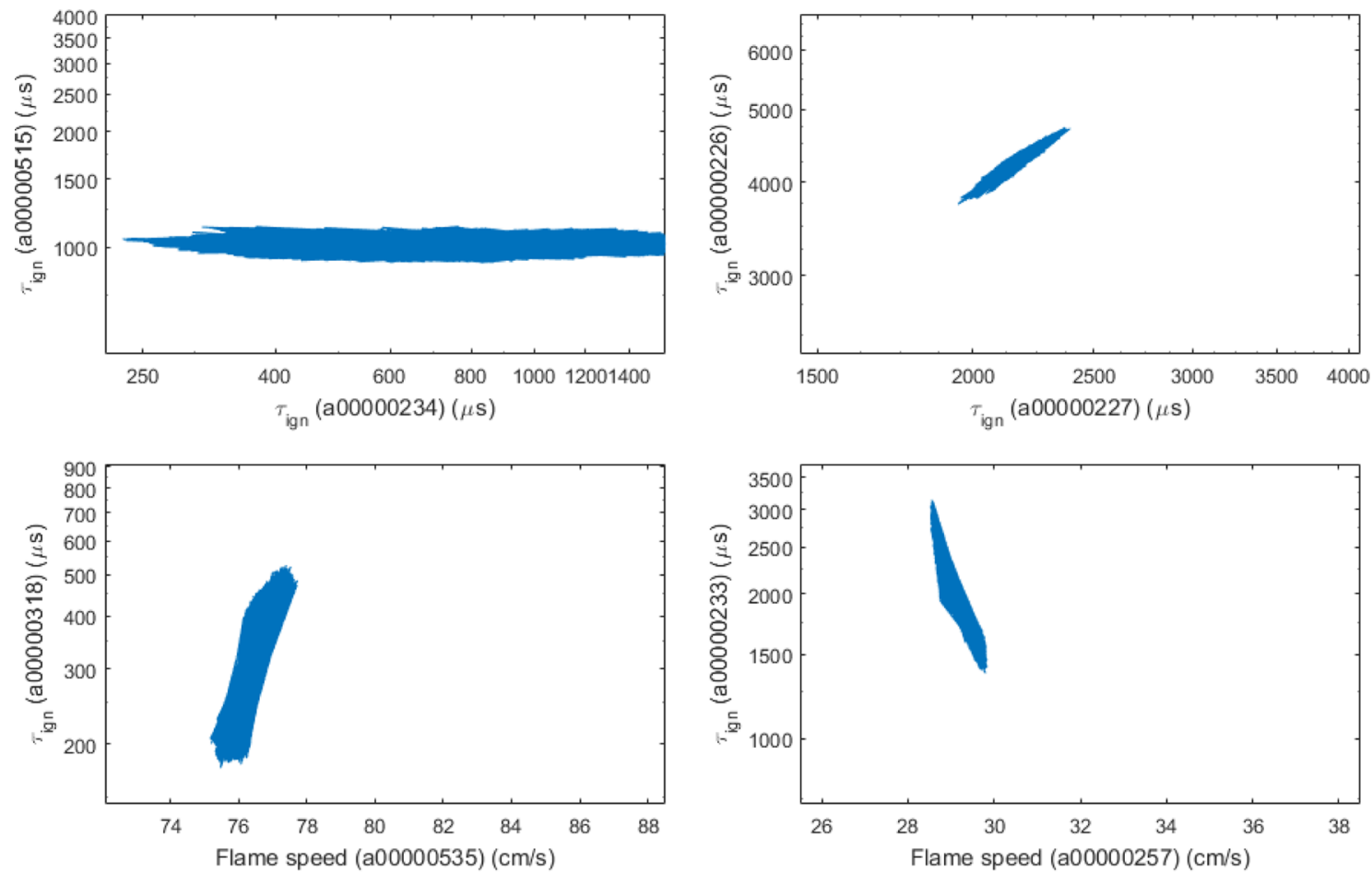

Figure 9. Two-dimensional projections of feasible set $F$ on QoI pairs. The axes are QoI values. Their ranges represent the uncertainty bounds.

Inspection of the results displayed in Figure 10 highlights several features. All optimization methods result in parameter sets that produce a better agreement with the experiment than the original set composed of literature recommendations. The LS-H optimization, constrained only to the prior uncertainty ranges of parameters, results in the lowest average deviation, as expected, but at the expense of violating uncertainty bounds of 13 experimental QoI. Only the LS-F and $1 \mathrm{~N}-\mathrm{F}$ optimization methods, with additional constraints to the QoI uncertainties, do not violate any of the QoI bounds, by design. The average deviation produced by LS-F is larger but not significantly larger than that of LS-H. The $1 \mathrm{~N}-\mathrm{F}$ method gives a larger average deviation, yet it changes the least number of variables, as shown in Figure S2 of the Supporting Information. The reaction model corresponding to the LS-F optimization can be found in Table S7 of the Supporting Information.

An explicit comparison is shown for some of the QoI in Figures 11-17 as well as in Figures S3-S7 of the Supporting Information. The visual observation is that all of the optimized models seem to perform with about the same overall quality; some models do better for one set of conditions, while others are closer to other experimental data sets (see Figures 11-13 and 17 and Figures S3-S5 of the Supporting Information). The shock-tube ignition delay times show a larger variation between different models. The problem here could lie with the incomplete instrumental model ${ }^{182}$ used in the simulation of ignition phenomena, because it does not capture the "nonidealities" of shock-tube experiments with sufficient detail ${ }^{135}$ or the development of a mild-ignition regime, ${ }^{140}$ which is not entirely driven by chemistry. These factors are especially under suspicion in the inconsistent ignition delay targets. Generally, the laminar flame speeds are predicted better by all models, with all simulations falling within the uncertainty bounds of experimental observations (see Figures 14-17 and
Figures S6 and S7 of the Supporting Information), reflecting perhaps the higher experimental accuracy of the measurements. ${ }^{183}$

5.4. Model Prediction. As was mentioned earlier, one of the key features of the B2BDC methodology is prediction on the feasible set. The existence of the feasible set is established by forming a dataset and examining its consistency, the procedure that can be referred to as model validation. Once the feasible set is established and the model is validated, one can examine the prediction of a model for a QoI that was not included in the validating dataset, referred to as a blind prediction.

First, we made blind predictions for experimentally observed QoI that were not included in the dataset. The results are reported in Figure 17; they include three sets of ignition delay times and one set of laminar flame speeds. The two sets of ignition delays, displayed in the left two panels of Figure 17, are those measured in highly dilute mixtures. In these cases, the predictions of all of the models are grouped closely together. On the other hand, the predictions for the other two cases, ignition delays (top right) and laminar flame speeds (bottom right) for non-dilute mixtures, show significant differences. The predictions of B2BDC-optimized models are all grouped together and are essentially within the reported uncertainties of the experimental observations. The initial model predicts the ignition delay times within their uncertainties and the laminar flame speeds reasonably close to their upper uncertainty bounds. The model of Varga et al. ${ }^{12}$ substantially overshoots the upper uncertainty bounds in both cases.

In the next test of blind prediction, we focused on what one may consider extreme operating conditions of a combustor, having a fuel with a low heating value at low temperatures and high pressures. Specifically, we selected a fuel mixture containing $1.0 \% \mathrm{H}_{2}, 5.3 \% \mathrm{CO}, 42.7 \% \mathrm{H}_{2} \mathrm{O}$, and $51.1 \% \mathrm{CO}_{2}$ 
1.2

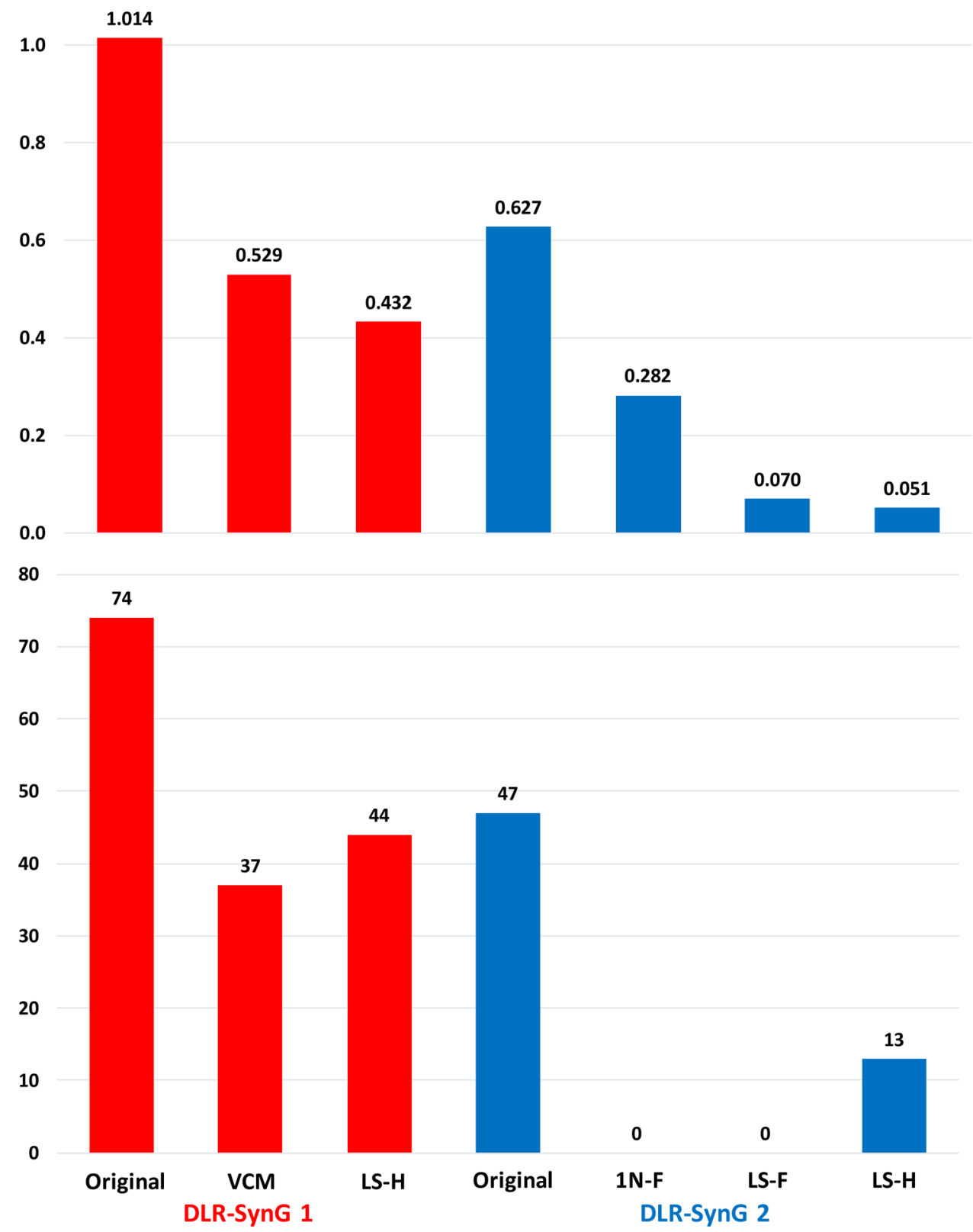

Figure 10. (Top) Average sum-of-squares deviations of the optimized model predictions from the experimental observations. (Bottom) Number of bound violations, i.e., when model-predicted QoI values are outside their respective uncertainty bounds. The individual bars correspond to the indicated parameter sets. "Original" represents the initial literature value set (Table S5 of the Supporting Information), and the rest of the values designate the optimization methods of the present work. Colored in red are results obtained with the DLR-SynG 1 dataset, and colored in blue are those obtained with the DLR-SynG 2 dataset.

that is mixed with preheated air under fuel-lean conditions, $\phi=0.5, p=12$ bar, and $T=720-820 \mathrm{~K}$.

The model predictions are displayed in Figure 18, along with those of Varga et al. ${ }^{12}$ Also shown, as black vertical lines, are uncertainty intervals computed using B2BDC with the DLRSynG 2 dataset. These intervals reflect all of the uncertainty information on the DLR-SynG 2 dataset, those of the parameters, and those of the dataset targets. Inspection of the results depicted in Figure 18 indicates that all models but one, LS-H, predict the new target within the B2BDC-predicted bounds. The LS-H predictions are definitely outside the bounds. This outcome is not unexpected, as suggested by our Conclusion.

\section{CONCLUSION}

Developing predictive models ${ }^{2}$ has become the goal in much of the modeling studies of reaction systems. Numerical optimization of complex reaction networks, of the kind that guided the development of GRI-Mech, ${ }^{2,5,9}$ has now been accepted as one of the underlying methods in this pursuit (see, e.g., recent publications $\left.{ }^{12,63,127}\right)$. In the language of the present work, this is the LS-H approach, a least-squares minimization constrained to a priori selected parameter ranges. The results of the present study, however, demonstrate that the LS-H optimization may miss some critical information on the model-data system. 

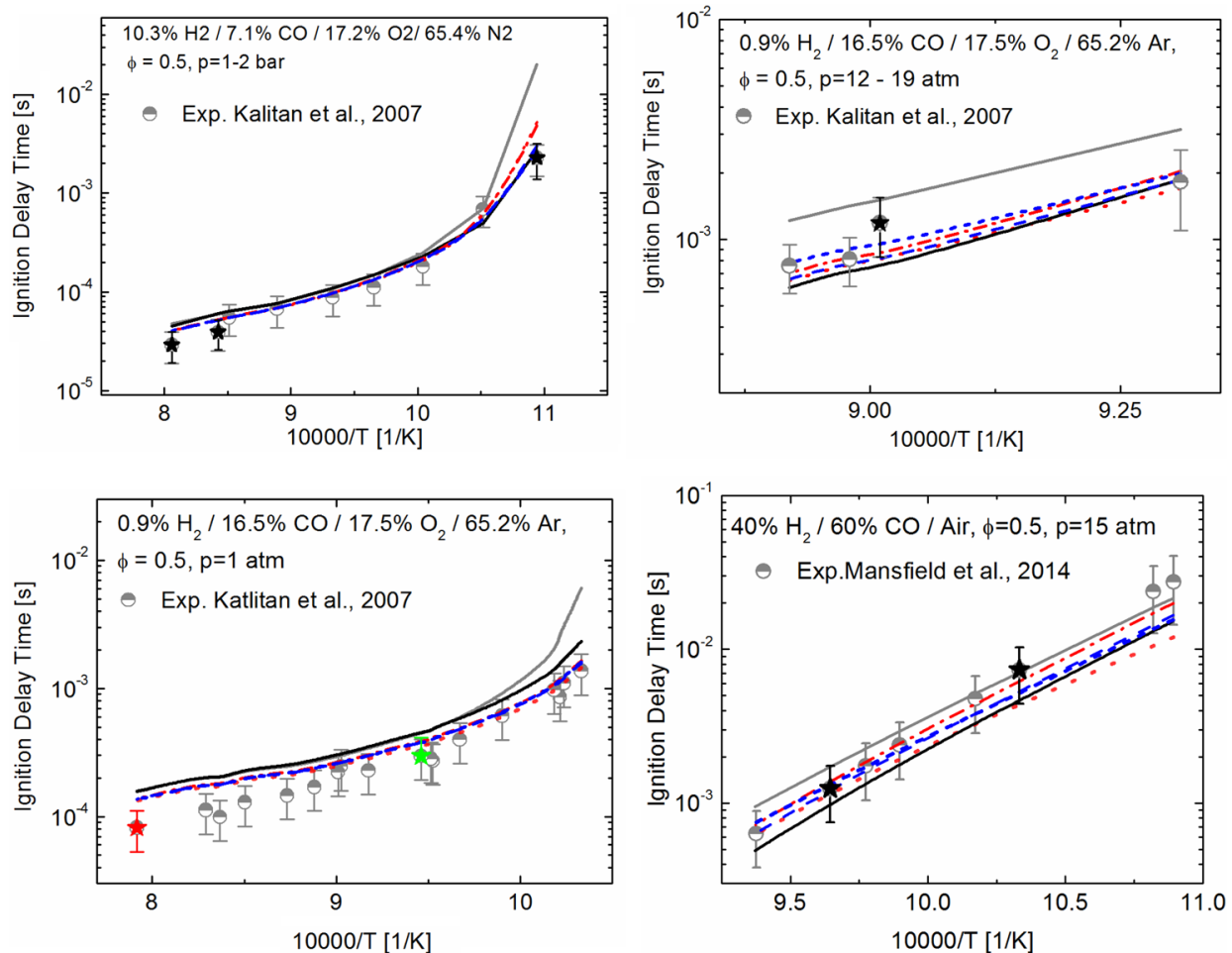

Figure 11. Ignition delay times: experimental data, ${ }^{61,79}$ symbols; initial model, black line; Varga et al. ${ }^{12}$ model, gray line; LS-H, red dotted line; VCM, red dash-dotted line; LS-F, blue dashed line; and 1N-F, blue short dashed line. Black stars are targets of the DLR-SynG 2 dataset; red stars are selfinconsistent targets; and green stars are targets deleted from the DLR-SynG 1 dataset.
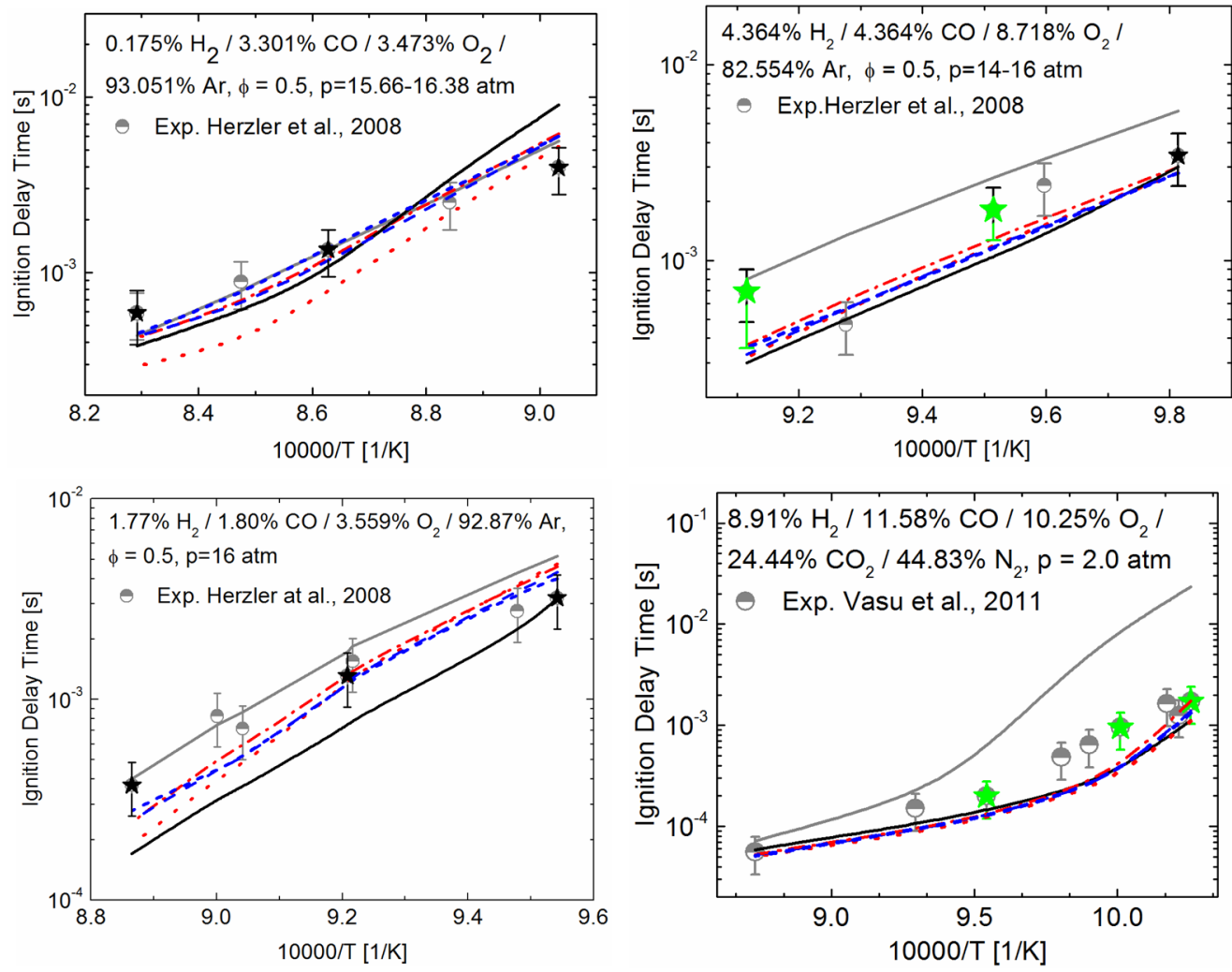

Figure 12. Ignition delay times: experimental data, ${ }^{58,108}$ symbols; initial model, black line; Varga et al. ${ }^{12}$ model, gray line; LS-H, red dotted line; VCM, red dash-dotted line; LS-F, blue dashed line; and 1N-F, blue short dashed line. Black stars are targets of the DLR-SynG 2 dataset, and green stars are targets deleted from the DLR-SynG 1 dataset.

It has been known for some time (see the study by Frenklach ${ }^{3}$ and references cited therein) that it is rather unproductive to search for a single optimal point in analysis of chemical kinetics, because the nature of the problem leads to correlated regions in 

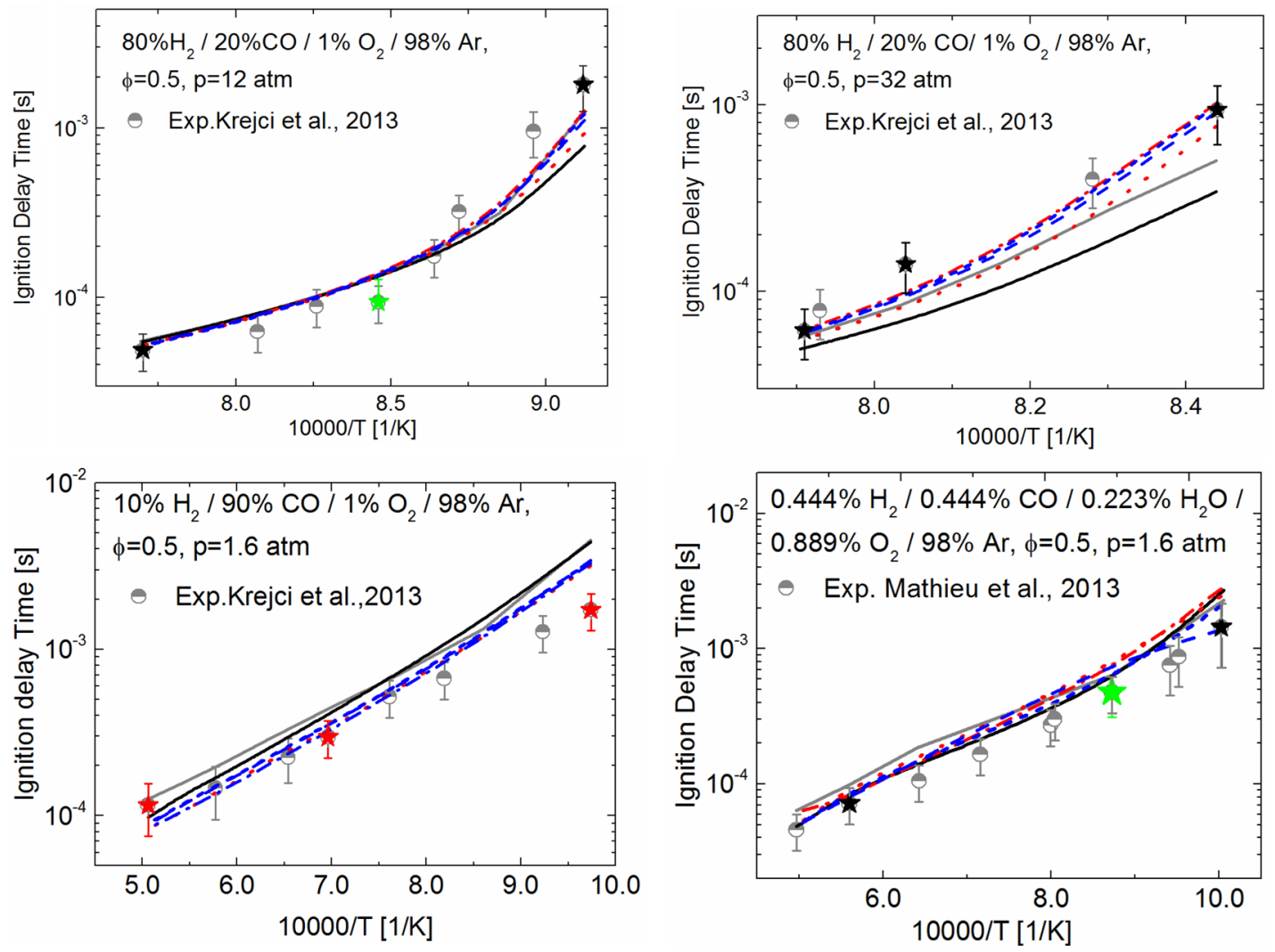

Figure 13. Ignition delay times: experimental data ${ }^{69,80}$ symbols; initial model, black line; Varga et al. ${ }^{12}$ model, gray line; LS-H, red dotted line; VCM, red dash-dotted line; LS-F, blue dashed line; and IN-F, blue short dashed line. Black stars are targets of the DLR-SynG 2 dataset; red stars are selfinconsistent targets; and green stars are targets deleted from the DLR-SynG 1 dataset.
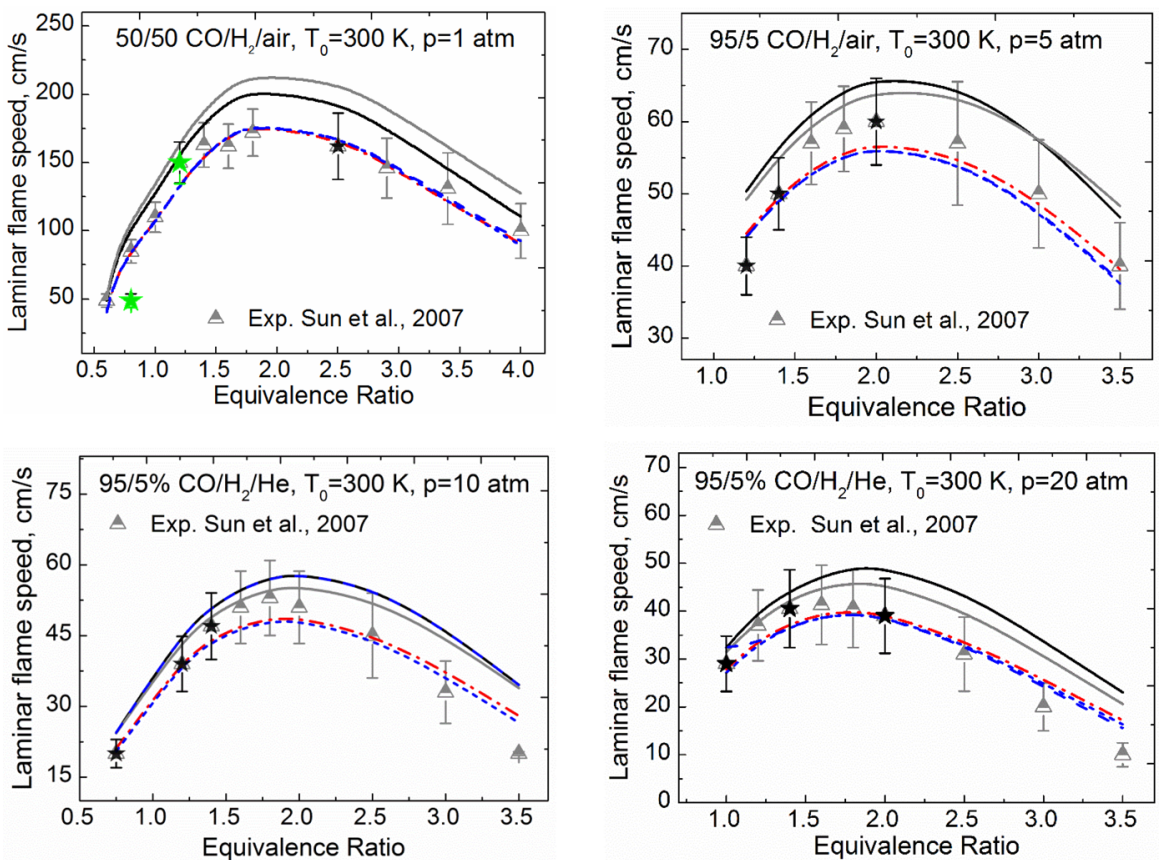

Figure 14. Laminar flame speeds: experimental data, ${ }^{101}$ symbols; initial model, black line; Varga et al. ${ }^{12}$ model, gray line; LS-H, red dotted line; VCM, red dash-dotted line; LS-F, blue dashed line; and 1N-F, blue short dashed line. Black stars are targets of the DLR-SynG 2 dataset, and green stars are targets deleted from the DLR-SynG 1 dataset.

parameter space, having many (if not infinite number) of such optimal points with practically indistinguishable predictions. The present results further demonstrate such outcomes.
Whether it is a statistically established confidence region ${ }^{3}$ (or credible region in the present Bayesian terminology) or a deterministically defined feasible set, ${ }^{15,21}$ analysis based 

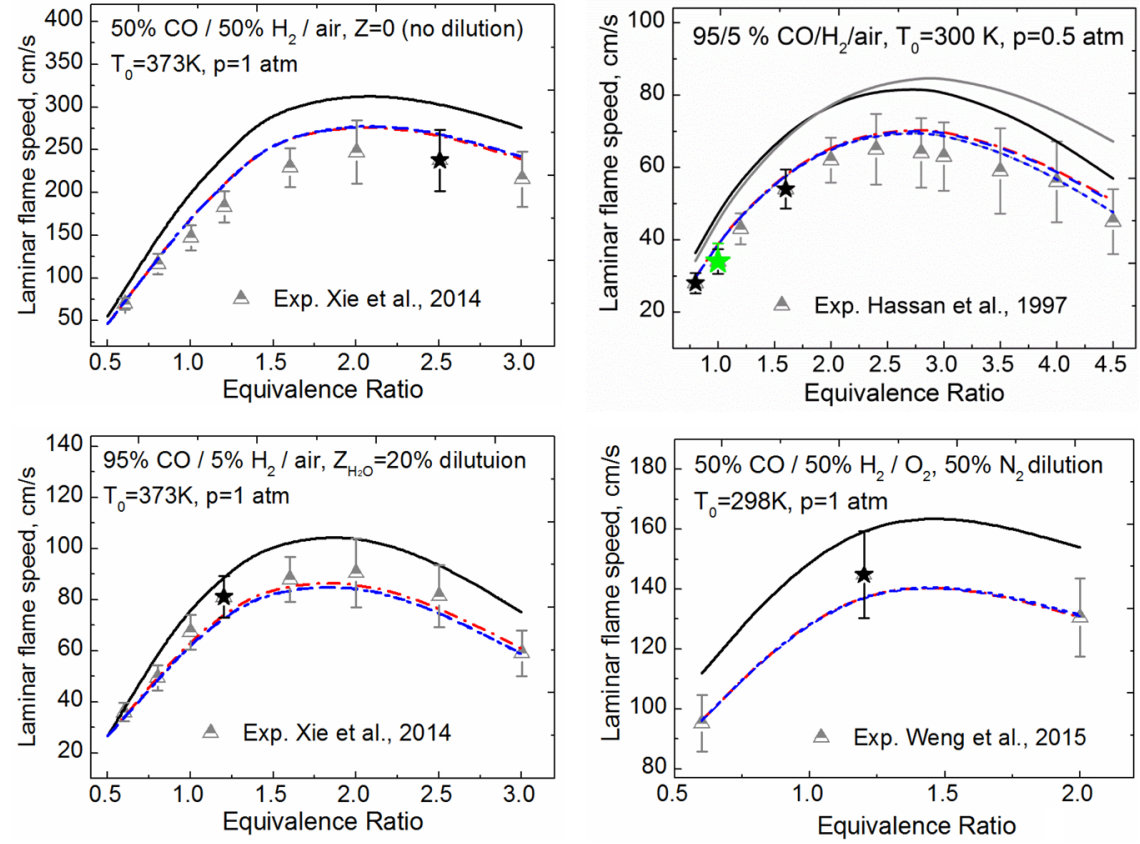

Figure 15. Laminar flame speeds: experimental data, ${ }^{56,111,114}$ symbols; initial model, black line; Varga et al. ${ }^{12}$ model, gray line; LS-H, red dotted line; VCM, red dash-dotted line; LS-F, blue dashed line; and 1N-F, blue short dashed line. Black stars are targets of the DLR-SynG 2 dataset, and green stars are targets deleted from the DLR-SynG 1 dataset.
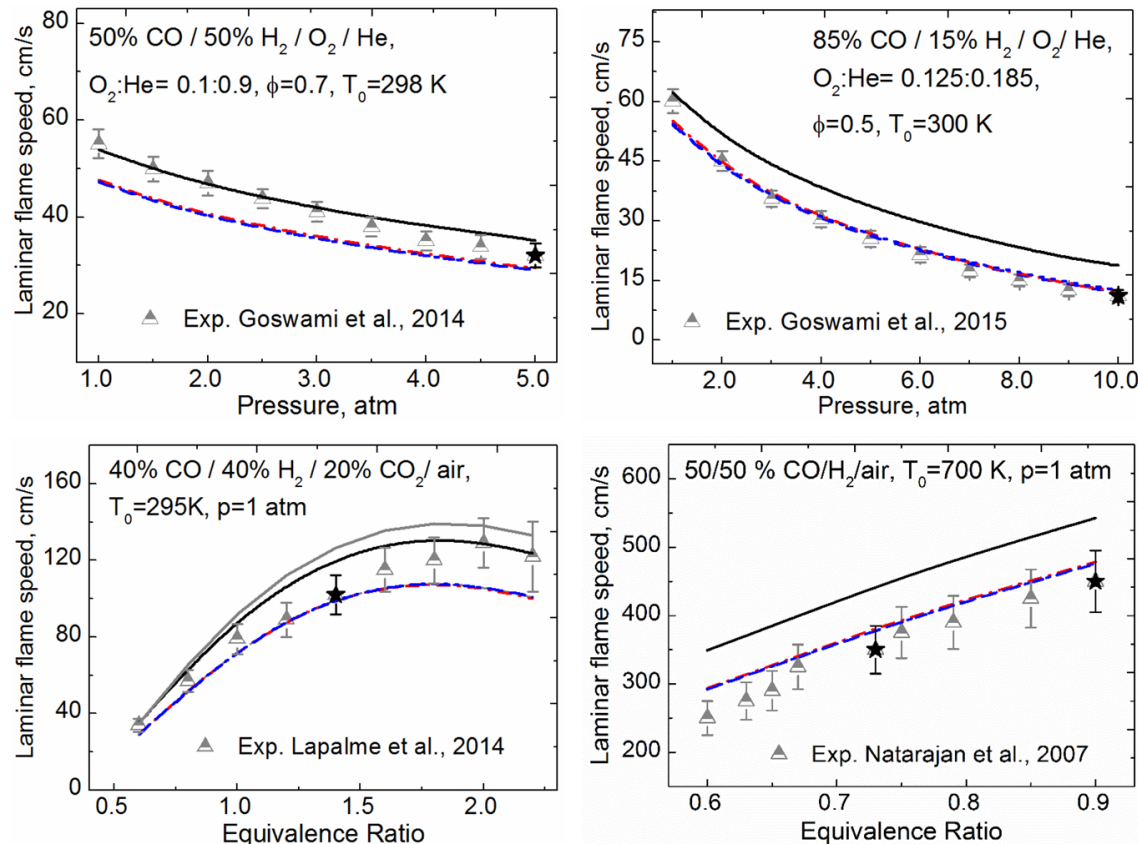

Figure 16. Laminar flame speeds: experimental data, ${ }^{53,54,71,86}$ symbols; initial model, black line; Varga et al. ${ }^{12}$ model, gray line; LS-H, red dotted line; VCM, red dash-dotted line; LS-F, blue dashed line; and IN-F, blue short dashed line. Black stars are targets of the DLR-SynG 2 dataset.

on these regions of "optimality" should be more informative. Indeed, as we saw with the present results, the LS-H minimization produces the lowest value deviation; however, there are a substantial number of individual predictions that exceed the prescribed experimental uncertainty. The practical implication of such an outcome can be paraphrased as follows: the LS-H optimization hides the truth by averaging good with bad.

On the other hand, the consistency analysis of B2BDC, probing the feasible set existence, immediately identified inconsistent experimental targets. This mathematical result does not identify whether the problem is with the model itself, its parameter values, or experimental observations (these are the questions for the combustion and kinetic scientists to resolve) but does identify where to look.

For the particular system that we analyzed, the suspicion is on the instrumental models used to simulate the ignition. The future will tell if our present speculation on the possible source of the inconsistency is correct or not. What is definite, however, 

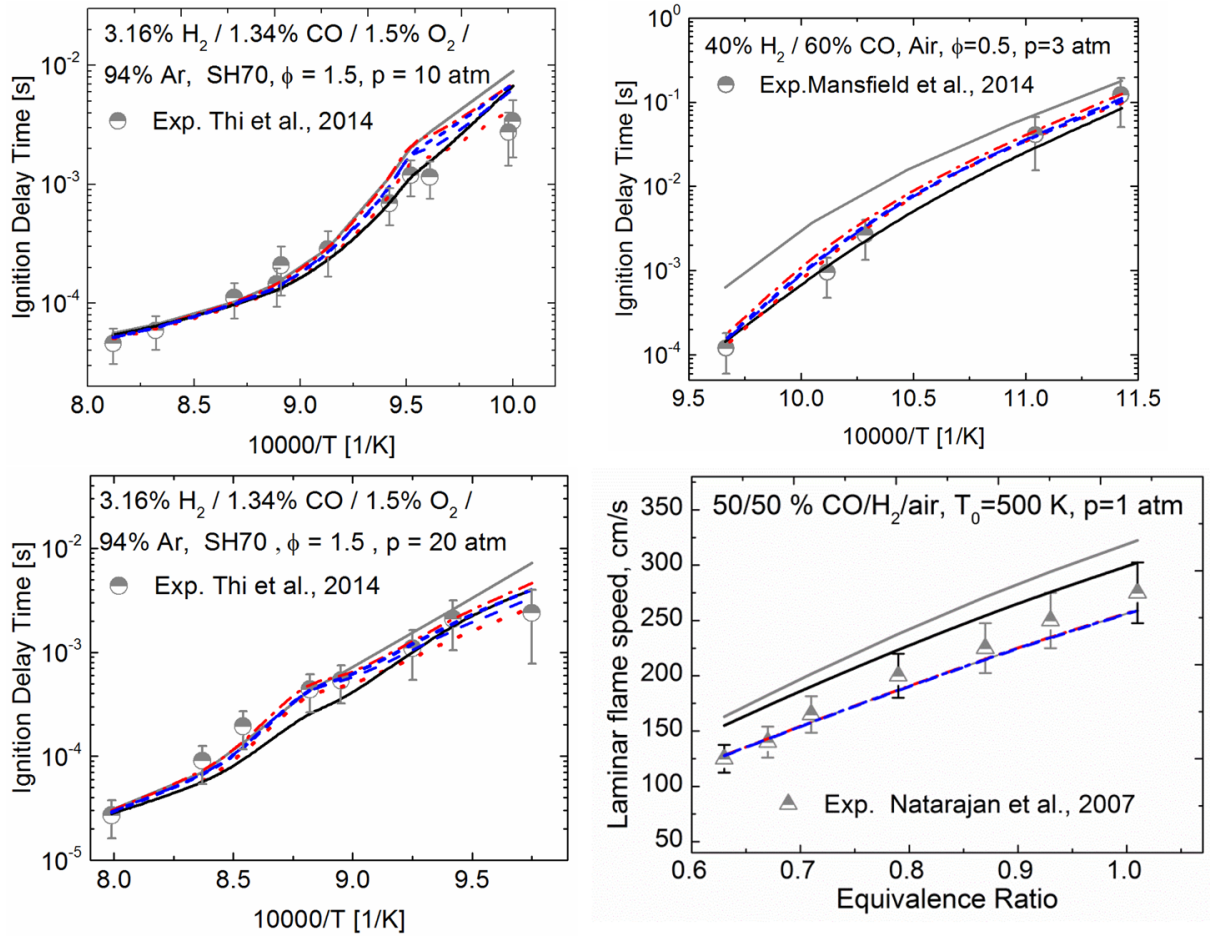

Figure 17. Ignition delay times ${ }^{79,104}$ and laminar flame speeds: ${ }^{86}$ experimental data, symbols; initial model, black line; Varga et al. ${ }^{12}$ model, gray line; LS-H, red dotted line; VCM, red dash-dotted line; LS-F, blue dashed line; and 1N-F, blue short dashed line.

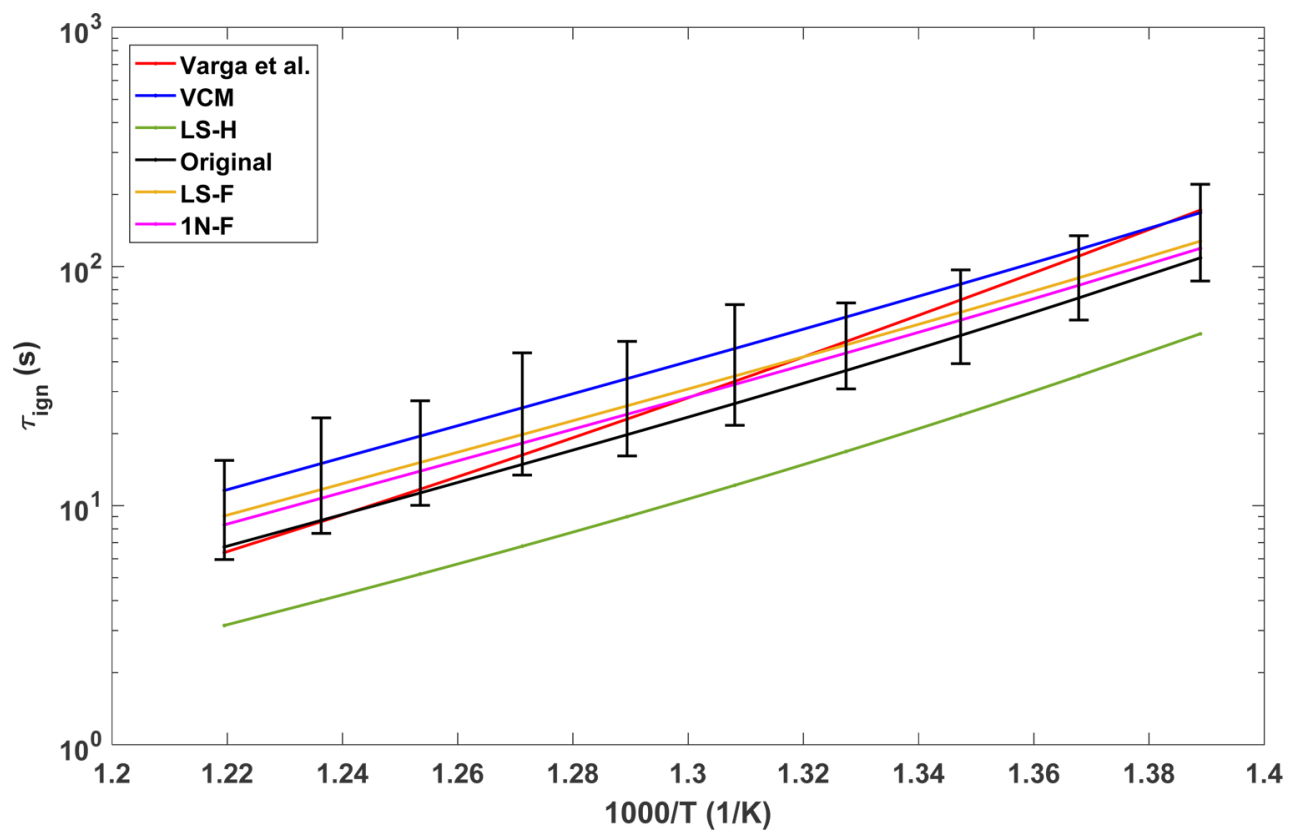

Figure 18. Ignition delay times: initial model, black solid line; Varga et al. ${ }^{12}$ model, red solid line; LS-H, green solid line; VCM, blue solid line; LS-F, yellow solid line; $1 \mathrm{~N}-\mathrm{F}$, purple solid line; and uncertainty intervals, black vertical bars.

is that the feasible set analysis of B2BDC identified the problem otherwise hidden in "averaged" least squares optimization.

\section{ASSOCIATED CONTENT}

\section{S Supporting Information}

The Supporting Information is available free of charge on the ACS Publications website at DOI: 10.1021/acs.energyfuels.6b02319.

Ignition delay time measurements (Table S1), laminar flame speed measurements from experimental data for
PrIMe flame speed (Table S2), ignition delay QoI (Table S3), laminar flame speed QoI (Table S4), input reaction model (Table S5), model parameters (Table S6), relative deviations of the optimized model predictions from the experimental observations, corresponding to the cases depicted in Figure 10 (Figure S1), change in model parameters as a result of optimization with the DLR-SynG 2 dataset using LS-H and $1 \mathrm{~N}-\mathrm{F}$ methods (Figure S2), comparison of computed and experimental ignition delay times (Figures S3-S5), and comparison of computed 
and experimental laminar flame speeds (Figures S6 and S7) (PDF)

LS-F reaction model optimized on the DLR-SynG 2 dataset (mech.txt), thermodynamic data transport (thermo.txt), and transport data (transport.txt) (ZIP)

\section{AUTHOR INFORMATION}

\section{Corresponding Authors}

*E-mail: nadja.slavinskaya@dlr.de.

*E-mail: frenklach@berkeley.edu.

\section{ORCID}

M. Frenklach: 0000-0002-9174-3306

\section{Notes}

The authors declare no competing financial interest.

\section{ACKNOWLEDGMENTS}

The authors from the University of California, Berkeley acknowledge the support of the National Nuclear Security Administration, U.S. Department of Energy, under Award DENA0002375. The views and opinions of authors expressed herein do not necessarily state or reflect those of the United States Government or any agency thereof.

\section{REFERENCES}

(1) Box, G. E. P.; Hunter, W. G.; Hunter, J. S. Statistics for Experimenters. An Introduction to Design, Data Analysis, and Model Building; Wiley: New York, 1978.

(2) Frenklach, M. Transforming data into knowledge-Process Informatics for combustion chemistry. Proc. Combust. Inst. 2007, 31 (1), 125-140.

(3) Frenklach, M. Modeling. In Combustion Chemistry; Gardiner, W. C., Ed.; Springer-Verlag: New York, 1984; pp 423-453, DOI: 10.1007/978-1-4684-0186-8 7.

(4) Frenklach, M.; Wang, H.; Rabinowitz, M. J. Optimization and analysis of large chemical kinetic mechanisms using the solution mapping method-Combustion of methane. Prog. Energy Combust. Sci. 1992, 18, 47-73.

(5) Smith, G. P.; Golden, D. M.; Frenklach, M.; Moriarty, N. W.; Eiteneer, B.; Goldenberg, M.; Bowman, T.; Hanson, R. K.; Song, S.; Gardiner, W. C., Jr.; Lissianski, V. V.; Qin, Z. GRI-Mech 3.0; http:// www.me.berkeley.edu/gri_mech/.

(6) Frenklach, M. Systematic optimization of a detailed kinetic model using a methane ignition example. Combust. Flame 1984, 58, 69-72.

(7) Miller, D.; Frenklach, M. Sensitivity analysis and parameter estimation in dynamic modeling of chemical kinetics. Int. J. Chem. Kinet. 1983, 15, 677-696.

(8) Frenklach, M.; Miller, D. L. Statistically rigorous parameter estimation in dynamic modeling using approximate empirical models. AIChE J. 1985, 31 (3), 498-500.

(9) Frenklach, M.; Packard, A.; Feeley, R. Optimization of reaction models with solution mapping. In Modeling of Chemical Reactions; Carr, R. W., Ed.; Elsevier: New York, 2007; Vol. 42, pp 243-291, DOI: $10.1016 /$ S0069-8040(07)42006-4.

(10) Davis, S. G.; Joshi, A. V.; Wang, H.; Egolfopoulos, F. N. An optimized kinetic model of $\mathrm{H}_{2} / \mathrm{CO}$ combustion. Proc. Combust. Inst. 2005, 30 (1), 1283-1292.

(11) Varga, T.; Nagy, T.; Olm, C.; Zsély, I. G.; Pálvölgyi, R.; Valkó, É.; Vincze, G.; Cserháti, M.; Curran, H. J.; Turányi, T. Optimization of a hydrogen combustion mechanism using both direct and indirect measurements. Proc. Combust. Inst. 2015, 35 (1), 589-596.

(12) Varga, T.; Olm, C.; Nagy, T.; Zsély, I. G.; Valkó, É.; Pálvölgyi, R.; Curran, H. J.; Turányi, T. Development of a joint hydrogen and syngas combustion mechanism based on an optimization approach. Int. J. Chem. Kinet. 2016, 48 (8), 407-422.
(13) Fischer, M.; Jiang, X. A chemical kinetic modelling study of the combustion of $\mathrm{CH}_{4}-\mathrm{CO}-\mathrm{H}_{2}-\mathrm{CO}_{2}$ fuel mixtures. Combust. Flame 2016, 167, 274-293.

(14) Olm, C.; Zsély, I. G.; Varga, T.; Curran, H. J.; Turányi, T. Comparison of the performance of several recent syngas combustion mechanisms. Combust. Flame 2015, 162, 1793-1812.

(15) Frenklach, M.; Packard, A.; Seiler, P.; Feeley, R. Collaborative data processing in developing predictive models of complex reaction systems. Int. J. Chem. Kinet. 2004, 36 (1), 57-66.

(16) Frenklach, M. PrIMe; http://primekinetics.org.

(17) You, X.; Packard, A.; Frenklach, M. Process informatics tools for predictive modeling: Hydrogen combustion. Int. J. Chem. Kinet. 2012, 44 (2), 101-116.

(18) Feeley, R.; Seiler, P.; Packard, A.; Frenklach, M. Consistency of a reaction dataset. J. Phys. Chem. A 2004, 108 (44), 9573-9583.

(19) Russi, T.; Packard, A.; Feeley, R.; Frenklach, M. Sensitivity analysis of uncertainty in model prediction. J. Phys. Chem. A 2008, 112 (12), 2579-2588.

(20) Russi, T.; Packard, A.; Frenklach, M. Uncertainty quantification: Making predictions of complex reaction systems reliable. Chem. Phys. Lett. 2010, 499 (1-3), 1-8.

(21) Seiler, P.; Frenklach, M.; Packard, A.; Feeley, R. Numerical approaches for collaborative data processing. Optim. Eng. 2006, 7 (4), 459-478.

(22) Boyd, S.; Vandenberghe, L. Convex Optimization; Cambridge University Press: Cambridge, U.K., 2004.

(23) Li, X.; You, X.; Wu, F.; Law, C. K. Uncertainty analysis of the kinetic model prediction for high-pressure $\mathrm{H}_{2} / \mathrm{CO}$ combustion. Proc. Combust. Inst. 2015, 35 (1), 617-624.

(24) Jatale, A.; Smith, P. J.; Thornock, J. K.; Smith, S. T.; Hradisky, M. A validation of flare combustion efficiency predictions from large eddy simulations. J. Verif. Valid. Uncert. Quantification 2016, 1 (2), 021001.

(25) Slavinskaya, N. A.; Frank, P. A modelling study of aromatic soot precursors formation in laminar methane and ethene flames. Combust. Flame 2009, 156 (9), 1705-1722.

(26) Slavinskaya, N. A.; Riedel, U.; Dworkin, S. B.; Thomson, M. J. Detailed numerical modeling of PAH formation and growth in nonpremixed ethylene and ethane flames. Combust. Flame 2012, 159 (3), 979-995.

(27) Abián, M.; Giménez-López, J.; Bilbao, R.; Alzueta, M. U. Effect of different concentration levels of $\mathrm{CO}_{2}$ and $\mathrm{H}_{2} \mathrm{O}$ on the oxidation of CO: Experiments and modeling. Proc. Combust. Inst. 2011, 33 (1), 317-323.

(28) Alekseev, V. A.; Christensen, M.; Konnov, A. A. The effect of temperature on the adiabatic burning velocities of diluted hydrogen flames: A kinetic study using an updated mechanism. Combust. Flame 2015, 162 (5), 1884-1898.

(29) Alzueta, M. U.; Bilbao, R.; Glarborg, P. Inhibition and sensitization of fuel oxidation by $\mathrm{SO}_{2}$. Combust. Flame 2001, 127 (4), 2234-2251.

(30) Arustamyan, A. M.; Shakhnazaryan, I. K.; Philipossyan, A. G.; Nalbandyan, A. B. The kinetics and the mechanism of the oxidation of carbon monoxide in the presence of hydrogen. Int. J. Chem. Kinet. 1980, 12 (1), 55-75.

(31) Aung, K. T.; Hassan, M. I.; Faeth, G. M. Flame stretch interactions of laminar premixed hydrogen/air flames at normal temperature and pressure. Combust. Flame 1997, 109 (1-2), 1-24.

(32) Aung, K. T.; Hassan, M. I.; Faeth, G. M. Effects of pressure and nitrogen dilution on flame/stretch interactions of laminar premixed $\mathrm{H}_{2} / \mathrm{O}_{2} / \mathrm{N}_{2}$ flames. Combust. Flame 1998, 112 (1-2), 1-15.

(33) Baulch, D. L.; Bowman, C. T.; Cobos, C. J.; Cox, R. A.; Just, Th.; Kerr, J. A.; Pilling, M. J.; Stocker, D.; Troe, J.; Tsang, W.; Walker, R. W.; Warnatz, J. Evaluated kinetic data for combustion modeling: Supplement II. J. Phys. Chem. Ref. Data 2005, 34 (3), 757-1397.

(34) Bouvet, N.; Chauveau, C.; Gökalp, I.; Halter, F. Experimental studies of the fundamental flame speeds of syngas $\left(\mathrm{H}_{2} / \mathrm{CO}\right) /$ air mixtures. Proc. Combust. Inst. 2011, 33 (1), 913-920. 
(35) Bouvet, N.; Lee, S. Y.; Gökalp, I.; Santoro, R. Flame speed characteristics of syngas $\left(\mathrm{H}_{2} \mathrm{CO}\right)$ with straight burners for laminar premixed flames. Proceedings of the 3rd European Combustion Meeting (ECM) 2007; Crete, Greece, April 11-13, 2007; Vol. 3, pp 6-17.

(36) Burbano, H. J.; Pareja, J.; Amell, A. A. Laminar burning velocities and flame stability analysis of $\mathrm{H}_{2} / \mathrm{CO} /$ air mixtures with dilution of $\mathrm{N}_{2}$ and $\mathrm{CO}_{2}$. Int. J. Hydrogen Energy 2011, 36 (4), 32323242.

(37) Burke, M. P.; Chaos, M.; Dryer, F. L.; Ju, Y. Negative pressure dependence of mass burning rates of $\mathrm{H}_{2} / \mathrm{CO} / \mathrm{O}_{2} /$ diluent flames at low flame temperatures. Combust. Flame 2010, 157 (4), 618-631.

(38) Cavaliere, D. E.; Joannon, M. d.; Sabia, P.; Sirignano, M.; D'Anna, A. A comprehensive kinetic modeling of ignition of syngasair mixtures at low temperatures and high pressures. Combust. Sci. Technol. 2010, 182 (4-6), 692-701.

(39) Chaos, M.; Dryer, F. L. Syngas combustion kinetics and applications. Combust. Sci. Technol. 2008, 180 (6), 1053-1096.

(40) Dagaut, P. Experimental and kinetic modeling study of the reduction of $\mathrm{NO}$ by hydrocarbons and interactions with $\mathrm{SO}_{2}$ in a JSR at $1 \mathrm{~atm} \star$. Fuel 2003, 82 (9), 1033-1040.

(41) Dagaut, P.; Lecomte, F.; Mieritz, J.; Glarborg, P. Experimental and kinetic modeling study of the effect of $\mathrm{NO}$ and $\mathrm{SO}_{2}$ on the oxidation of $\mathrm{CO}-\mathrm{H}_{2}$ mixtures. Int. J. Chem. Kinet. 2003, 35 (11), 564575.

(42) Das, A. K.; Kumar, K.; Sung, C.-J. Laminar flame speeds of moist syngas mixtures. Combust. Flame 2011, 158 (2), 345-353.

(43) Dean, A. M.; Johnson, R. L. Shock tube studies of the $\mathrm{N}_{2} \mathrm{O} /$ $\mathrm{CH}_{4} / \mathrm{CO} / \mathrm{Ar}$ and $\mathrm{N}_{2} \mathrm{O} / \mathrm{C}_{2} \mathrm{H}_{6} / \mathrm{CO} / \mathrm{Ar}$ systems. Combust. Flame 1980, 37, 109-123.

(44) Dean, A. M.; Steiner, D. C.; Wang, E. E. A shock tube study of the $\mathrm{H}_{2} / \mathrm{O}_{2} / \mathrm{CO} / \mathrm{Ar}$ and $\mathrm{H}_{2} / \mathrm{N}_{2} \mathrm{O} / \mathrm{CO} / \mathrm{Ar}$ Systems: Measurement of the rate constant for $\mathrm{H}+\mathrm{N}_{2} \mathrm{O}=\mathrm{N}_{2}+\mathrm{OH}$. Combust. Flame 1978, 32, $73-83$.

(45) Dong, C.; Zhou, Q.; Zhao, Q.; Zhang, Y.; Xu, T.; Hui, S. Experimental study on the laminar flame speed of hydrogen/carbon monoxide/air mixtures. Fuel 2009, 88 (10), 1858-1863.

(46) Dowdy, D. R.; Smith, D. B.; Taylor, S. C.; Williams, A. The use of expanding spherical flames to determine burning velocities and stretch effects in hydrogen/air mixtures. Symp. Combust., [Proc.] 1991, 23 (1), 325-332.

(47) Egolfopoulos, F. N.; Law, C. K. An experimental and computational study of the burning rates of ultra-lean to moderately-rich $\mathrm{H}_{2} / \mathrm{O}_{2} / \mathrm{N}_{2}$ laminar flames with pressure variations. Symp. Combust., [Proc.] 1991, 23 (1), 333-340.

(48) Fotache, C. G.; Tan, Y.; Sung, C. J.; Law, C. K. Ignition of CO/ $\mathrm{H}_{2} / \mathrm{N}_{2}$ versus heated air in counterflow: Experimental and modeling results. Combust. Flame 2000, 120 (4), 417-426.

(49) Frassoldati, A.; Faravelli, T.; Ranzi, E. The ignition, combustion and flame structure of carbon monoxide/hydrogen mixtures. Note 1: Detailed kinetic modeling of syngas combustion also in presence of nitrogen compounds. Int. J. Hydrogen Energy 2007, 32 (15), 34713485 .

(50) Gardiner, W. C.; McFarland, M.; Morinaga, K.; Takeyama, T.; Walker, B. F. Initiation rate for shock-heated hydrogen-oxygen-carbon monoxide-argon mixtures as determined by $\mathrm{OH}$ induction time measurements. J. Phys. Chem. 1971, 75 (10), 1504-1509.

(51) Gersen, S.; Darmeveil, H.; Levinsky, H. The effects of CO addition on the autoignition of $\mathrm{H}_{2}, \mathrm{CH}_{4}$ and $\mathrm{CH}_{4} / \mathrm{H}_{2}$ fuels at high pressure in an RCM. Combust. Flame 2012, 159 (12), 3472-3475.

(52) Glarborg, P.; Kubel, D.; Dam-Johansen, K.; Chiang, H.-M.; Bozzelli, J. W. Impact of $\mathrm{SO}_{2}$ and $\mathrm{NO}$ on $\mathrm{CO}$ oxidation under postflame conditions. Int. J. Chem. Kinet. 1996, 28 (10), 773-790.

(53) Goswami, M.; Bastiaans, R. J. M.; Konnov, A. A.; de Goey, L. P. $\mathrm{H}$. Laminar burning velocity of lean $\mathrm{H}_{2}-\mathrm{CO}$ mixtures at elevated pressure using the heat flux method. Int. J. Hydrogen Energy 2014, 39 (3), 1485-1498.

(54) Goswami, M.; van Griensven, J. G. H.; Bastiaans, R. J. M.; Konnov, A. A.; de Goey, L. P. H. Experimental and modeling study of the effect of elevated pressure on lean high-hydrogen syngas flames. Proc. Combust. Inst. 2015, 35 (1), 655-662.

(55) Han, M.; Ai, Y.; Chen, Z.; Kong, W. Laminar flame speeds of $\mathrm{H}_{2} / \mathrm{CO}$ with $\mathrm{CO}_{2}$ dilution at normal and elevated pressures and temperatures. Fuel 2015, 148, 32-38.

(56) Hassan, M. I.; Aung, K. T.; Faeth, G. M. Properties of Laminar Premixed $\mathrm{CO} / \mathrm{H} /$ Air Flames at Various Pressures. J. Propul. Power 1997, 13 (2), 239-245.

(57) He, Y.; Wang, Z.; Weng, W.; Zhu, Y.; Zhou, J.; Cen, K. Effects of $\mathrm{CO}$ content on laminar burning velocity of typical syngas by heat flux method and kinetic modeling. Int. J. Hydrogen Energy 2014, 39 (17), 9534-9544.

(58) Herzler, J.; Naumann, C. Shock tube study of the ignition of lean $\mathrm{CO} / \mathrm{H}_{2}$ fuel blends at intermediate temperatures and high pressure. Combust. Sci. Technol. 2008, 180 (10-11), 2015-2028.

(59) Huang, Y.; Sung, C.; Eng, J. Laminar flame speeds of primary reference fuels and reformer gas mixtures. Combust. Flame 2004, 139 (3), 239-251.

(60) Jahn, G. Der Zündvorgang in Gasgemischen. Angew. Chem. 1934, 47 (36), 630-632.

(61) Kalitan, D. M.; Mertens, J. D.; Crofton, M. W.; Petersen, E. L. Ignition and oxidation of lean $\mathrm{CO} / \mathrm{H}_{2}$ fuel blends in air. J. Propul. Power 2007, 23 (6), 1291-1301.

(62) Karpov, V. P.; Lipatnikov, A. N.; Wolanski, P. Finding the markstein number using the measurements of expanding spherical laminar flames. Combust. Flame 1997, 109 (3), 436-448.

(63) Kéromnès, A.; Metcalfe, W. K.; Heufer, K. A.; Donohoe, N.; Das, A. K.; Sung, C.-J.; Herzler, J.; Naumann, C.; Griebel, P.; Mathieu, O.; Krejci, M. C.; Petersen, E. L.; Pitz, W. J.; Curran, H. J. An experimental and detailed chemical kinetic modeling study of hydrogen and syngas mixture oxidation at elevated pressures. Combust. Flame 2013, 160 (6), 995-1011.

(64) Kim, J. S.; Park, J.; Bae, D. S.; Vu, T. M.; Ha, J. S.; Kim, T. K. A study on methane-air premixed flames interacting with syngas-air premixed flames. Int. J. Hydrogen Energy 2010, 35 (3), 1390-1400.

(65) Kim, T. J.; Yetter, R. A.; Dryer, F. L. New results on moist CO oxidation: High pressure, high temperature experiments and comprehensive kinetic modeling. Symp. Combust., [Proc.] 1994, 25 (1), 759-766.

(66) Konnov, A. A. Remaining uncertainties in the kinetic mechanism of hydrogen combustion. Combust. Flame 2008, 152 (4), 507-528.

(67) Konnov, A. A. Implementation of the NCN pathway of promptNO formation in the detailed reaction mechanism. Combust. Flame 2009, 156 (11), 2093-2105.

(68) Konnov, A. A.; Dyakov, I. V.; de Ruyck, J. Nitric oxide formation in premixed flames of $\mathrm{H}_{2}+\mathrm{CO}+\mathrm{CO}_{2}$ and air. Proc. Combust. Inst. 2002, 29 (2), 2171-2177.

(69) Krejci, M. C.; Mathieu, O.; Vissotski, A. J.; Ravi, S.; Sikes, T. G.; Petersen, E. L.; Kérmonès, A.; Metcalfe, W.; Curran, H. J. Laminar flame speed and ignition delay time data for the kinetic modeling of hydrogen and syngas fuel blends. J. Eng. Gas Turbines Power 2013, 135 (2), 021503.

(70) Kwon, O. C.; Faeth, G. M. Flame/stretch interactions of premixed hydrogen-fueled flames: Measurements and predictions. Combust. Flame 2001, 124 (4), 590-610.

(71) Lapalme, D.; Seers, P. Influence of $\mathrm{CO}_{2}, \mathrm{CH}_{4}$, and initial temperature on $\mathrm{H}_{2} / \mathrm{CO}$ laminar flame speed. Int. J. Hydrogen Energy 2014, 39 (7), 3477-3486.

(72) Le Cong, T.; Dagaut, P.; Dayma, G. Oxidation of natural gas, natural gas/syngas mixtures, and effect of burnt gas recirculation: Experimental and detailed kinetic modeling. J. Eng. Gas Turbines Power 2008, 130 (4), 041502.

(73) Lewis, B.; Elbe, G. Combustion, Flames, and Explosions of Gases, 2rd ed.; Academic Press: New York, 1961; pp 731.

(74) Lewis, B.; Elbe, G. Combustion, Flames, and Explosions of Gases, 3rd ed.; Academic Press: Orlando, FL, 1987; pp 739.

(75) Li, H.-M.; Li, G.-X.; Sun, Z.-Y.; Zhou, Z.-H.; Li, Y.; Yuan, Y. Effect of dilution on laminar burning characteristics of $\mathrm{H}_{2} / \mathrm{CO} / \mathrm{CO}_{2} /$ 
air premixed flames with various hydrogen fractions. Exp. Therm. Fluid Sci. 2016, 74, 160-168.

(76) Li, J.; Zhao, Z.; Kazakov, A.; Chaos, M.; Dryer, F. L.; Scire, J. J. A comprehensive kinetic mechanism for $\mathrm{CO}, \mathrm{CH}_{2} \mathrm{O}$, and $\mathrm{CH}_{3} \mathrm{OH}$ combustion. Int. J. Chem. Kinet. 2007, 39 (3), 109-136.

(77) Linteris, G. T.; Yetter, R. A.; Brezinsky, K.; Dryer, F. L. Hydroxyl radical concentration measurements in moist carbon monoxide oxidation in a chemical kinetic flow reactor. Combust. Flame 1991, 86 (1-2), 162-170.

(78) Lohöfener, B.; Roungos, E.; Voss, S.; Trimis, D. Burning velocities of low calorific value hydrogen and carbon monoxide gas mixtures. Proceedings of the 2nd Heat Flux Burner Workshop; Warsaw, Poland, July 29, 2012.

(79) Mansfield, A. B.; Wooldridge, M. S. High-pressure lowtemperature ignition behavior of syngas mixtures. Combust. Flame 2014, 161 (9), 2242-2251.

(80) Mathieu, O.; Kopp, M. M.; Petersen, E. L. Shock-tube study of the ignition of multi-component syngas mixtures with and without ammonia impurities. Proc. Combust. Inst. 2013, 34 (2), 3211-3218.

(81) McLean, I. C.; Smith, D. B.; Taylor, S. C. The use of carbon monoxide/hydrogen burning velocities to examine the rate of the $\mathrm{CO}$ +OH reaction. Symp. Combust., [Proc.] 1994, 25 (1), 749-757.

(82) Mertens, J. D.; Kalitan, D. M.; Barrett, A. B.; Petersen, E. L. Determination of the rate of $\mathrm{H}+\mathrm{O}_{2}+\mathrm{M} \rightarrow \mathrm{HO}_{2}+\mathrm{M}\left(\mathrm{M}=\mathrm{N}_{2}, \mathrm{Ar}, \mathrm{H}_{2} \mathrm{O}\right)$ from ignition of syngas at practical conditions. Proc. Combust. Inst. 2009, 32 (1), 295-303.

(83) Mittal, G.; Sung, C.-J.; Yetter, R. A. Autoignition of $\mathrm{H}_{2} / \mathrm{CO}$ at elevated pressures in a rapid compression machine. Int. J. Chem. Kinet. 2006, 38 (8), 516-529.

(84) Mueller, M. A.; Yetter, R. A.; Dryer, F. L. Flow reactor studies and kinetic modeling of the $\mathrm{H}_{2} / \mathrm{O}_{2} / \mathrm{NO}_{\mathrm{x}}$ and $\mathrm{CO} / \mathrm{H}_{2} \mathrm{O} / \mathrm{O}_{2} / \mathrm{NO}_{\mathrm{x}}$ reactions. Int. J. Chem. Kinet. 1999, 31 (10), 705-724.

(85) Natarajan, J.; Kochar, Y.; Lieuwen, T.; Seitzman, J. Pressure and preheat dependence of laminar flame speeds of $\mathrm{H}_{2} / \mathrm{CO} / \mathrm{CO}_{2} / \mathrm{O}_{2} / \mathrm{He}$ mixtures. Proc. Combust. Inst. 2009, 32 (1), 1261-1268.

(86) Natarajan, J.; Lieuwen, T.; Seitzman, J. Laminar flame speeds of $\mathrm{H}_{2} / \mathrm{CO}$ mixtures: Effect of $\mathrm{CO}_{2}$ dilution, preheat temperature, and pressure. Combust. Flame 2007, 151 (1-2), 104-119.

(87) Naumann, C.; Herzler, J.; Griebel, P.; Curran, H. J.; Kéromnès, A.; Mantzaras, I. $\mathrm{H}_{2}$-IGCC Project: Results of ignition delay times for hydrogen-rich and syngas fuel mixtures measured. In 7th Framework Programme: Energy-Tren-Energy-Clean Coal Technologies; Institute of Combustion Technology, German Aerospace Center (DLR): Stuttgart, Germany, 2011.

(88) Nilsson, E. J. K.; Konnov, A. A. Role of HOCO chemistry in syngas combustion. Energy Fuels 2016, 30 (3), 2443-2457.

(89) Ó Conaire, M.; Curran, H. J.; Simmie, J. M.; Pitz, W. J.; Westbrook, C. K. A comprehensive modeling study of hydrogen oxidation. Int. J. Chem. Kinet. 2004, 36 (11), 603-622.

(90) Peschke, W. T.; Spadaccini, L. J. Determination of Autoignition and Flame Speed Characteristics of Coal Gases Having Medium Heating Values; Electric Power Research Institute (EPRI): East Hartford, CT, 1985; EPRI AP-4291.

(91) Petersen, E. L.; Kalitan, D. M.; Barrett, A. B.; Reehal, S. C.; Mertens, J. D.; Beerer, D. J.; Hack, R. L.; McDonell, V. G. New syngas/air ignition data at lower temperature and elevated pressure and comparison to current kinetics models. Combust. Flame 2007, 149 (1-2), 244-247.

(92) Petrova, M.; Williams, F. A small detailed chemical-kinetic mechanism for hydrocarbon combustion. Combust. Flame 2006, 144 (3), 526-544

(93) Prathap, C.; Ray, A.; Ravi, M. R. Investigation of nitrogen dilution effects on the laminar burning velocity and flame stability of syngas fuel at atmospheric condition. Combust. Flame 2008, 155 (12), $145-160$.

(94) Ratna Kishore, V.; Ravi, M. R.; Ray, A. Adiabatic burning velocity and cellular flame characteristics of $\mathrm{H}_{2}-\mathrm{CO}-\mathrm{CO}_{2}$-air mixtures. Combust. Flame 2011, 158 (11), 2149-2164.
(95) Santner, J.; Dryer, F. L.; Ju, Y. The effects of water dilution on hydrogen, syngas, and ethylene flames at elevated pressure. Proc. Combust. Inst. 2013, 34 (1), 719-726.

(96) Saxena, P.; Williams, F. A. Testing a small detailed chemicalkinetic mechanism for the combustion of hydrogen and carbon monoxide. Combust. Flame 2006, 145 (1-2), 316-323.

(97) Scholte, T. G.; Vaags, P. B. Burning velocities of mixtures of hydrogen, carbon monoxide and methane with air. Combust. Flame 1959, 3, 511-524.

(98) Singh, D.; Nishiie, T.; Tanvir, S.; Qiao, L. An experimental and kinetic study of syngas/air combustion at elevated temperatures and the effect of water addition. Fuel 2012, 94, 448-456.

(99) Sivaramakrishnan, R.; Comandini, A.; Tranter, R. S.; Brezinsky, K.; Davis, S. G.; Wang, H. Combustion of $\mathrm{CO} / \mathrm{H}_{2}$ mixtures at elevated pressures. Proc. Combust. Inst. 2007, 31 (1), 429-437.

(100) Starik, A. M.; Titova, N. S.; Sharipov, A. S.; Kozlov, V. E. Syngas oxidation mechanism. Combust., Explos. Shock Waves 2010, 46 (5), 491-506.

(101) Sun, H.; Yang, S. I.; Jomaas, G.; Law, C. K. High-pressure laminar flame speeds and kinetic modeling of carbon monoxide/ hydrogen combustion. Proc. Combust. Inst. 2007, 31 (1), 439-446.

(102) Sun, S.; Meng, S.; Zhao, Y.; Xu, H.; Guo, Y.; Qin, Y. Experimental and theoretical studies of laminar flame speed of $\mathrm{CO} / \mathrm{H}_{2}$ in $\mathrm{O}_{2} / \mathrm{H}_{2} \mathrm{O}$ atmosphere. Int. J. Hydrogen Energy 2016, 41 (4), 32723283.

(103) Thi, L. D.; Zhang, Y.; Fu, J.; Huang, Z.; Zhang, Y. Study on ignition delay of multi-component syngas using shock tube. Can. J. Chem. Eng. 2014, 92 (5), 861-870.

(104) Thi, L. D.; Zhang, Y.; Huang, Z. Shock tube study on ignition delay of multi-component syngas mixtures - Effect of equivalence ratio. Int. J. Hydrogen Energy 2014, 39 (11), 6034-6043.

(105) Vagelopoulos, C. M.; Egolfopoulos, F. N. Laminar flame speeds and extinction strain rates of mixtures of carbon monoxide with hydrogen, methane, and air. Symp. Combust., [Proc.] 1994, 25 (1), $1317-1323$.

(106) Vagelopoulos, C. M.; Egolfopoulos, F. N.; Law, C. K. Further considerations on the determination of laminar flame speeds with the counterflow twin-flame technique. Symp. Combust., [Proc.] 1994, 25 (1), 1341-1347.

(107) Vandooren, J.; van Tiggelen, P. J.; Pauwels, J. F. Experimental and modeling studies of a rich $\mathrm{H}_{2} / \mathrm{CO} / \mathrm{N}_{2} \mathrm{O} / \mathrm{Ar}$ flame. Combust. Flame 1997, 109 (4), 647-668.

(108) Vasu, S. S.; Davidson, D. F.; Hanson, R. K. Shock tube study of syngas ignition in rich $\mathrm{CO}_{2}$ mixtures and determination of the rate of $\mathrm{H}+\mathrm{O}_{2}+\mathrm{CO}_{2} \rightarrow \mathrm{HO}_{2}+\mathrm{CO}_{2}$. Energy Fuels 2011, 25 (3), 990-997.

(109) Voss, S.; Hartl, S.; Hasse, C. Determination of laminar burning velocities for lean low calorific $\mathrm{H}_{2} / \mathrm{N}_{2}$ and $\mathrm{H}_{2} / \mathrm{CO} / \mathrm{N}_{2}$ gas mixtures. Int. J. Hydrogen Energy 2014, 39 (34), 19810-19817.

(110) Wang, Z. H.; Weng, W. B.; He, Y.; Li, Z. S.; Cen, K. F. Effect of $\mathrm{H}_{2} / \mathrm{CO}$ ratio and $\mathrm{N}_{2} / \mathrm{CO}_{2}$ dilution rate on laminar burning velocity of syngas investigated by direct measurement and simulation. Fuel 2015, $141,285-292$.

(111) Weng, W. B.; Wang, Z. H.; He, Y.; Whiddon, R.; Zhou, Y. J.; Li, Z. S.; Cen, K. F. Effect of $\mathrm{N}_{2} / \mathrm{CO}_{2}$ dilution on laminar burning velocity of $\mathrm{H}_{2}-\mathrm{CO}-\mathrm{O}_{2}$ oxy-fuel premixed flame. Int. J. Hydrogen Energy 2015, 40 (2), 1203-1211.

(112) Wu, F.; Kelley, A. P.; Tang, C.; Zhu, D.; Law, C. K. Measurement and correlation of laminar flame speeds of $\mathrm{CO}$ and $\mathrm{C}_{2}$ hydrocarbons with hydrogen addition at atmospheric and elevated pressures. Int. J. Hydrogen Energy 2011, 36 (20), 13171-13180.

(113) Xia, Y. Ph.D. Thesis, Aberystwyth University, Aberystwyth, U.K., 2000.

(114) Xie, Y.; Wang, J.; Xu, N.; Yu, S.; Huang, Z. Comparative study on the effect of $\mathrm{CO}_{2}$ and $\mathrm{H}_{2} \mathrm{O}$ dilution on laminar burning characteristics of $\mathrm{CO} / \mathrm{H}_{2} /$ air mixtures. Int. J. Hydrogen Energy 2014, 39 (7), 3450-3458.

(115) Xie, Y.; Wang, J.; Xu, N.; Yu, S.; Zhang, M.; Huang, Z. Thermal and chemical effects of water addition on laminar burning velocity of syngas. Energy Fuels 2014, 28 (5), 3391-3398. 
(116) Yetter, R. A.; Dryer, F. L.; Rabitz, H. A comprehensive reaction mechanism for carbon monoxide/hydrogen/oxygen kinetics. Combust. Sci. Technol. 1991, 79 (1-3), 97-128.

(117) Yetter, R. A.; Dryer, F. L.; Rabitz, H. Flow reactor studies of carbon monoxide/hydrogen/oxygen kinetics. Combust. Sci. Technol. 1991, 79 (1-3), 129-140.

(118) Zhang, X.; Huang, Z.; Zhang, Z.; Zheng, J.; Yu, W.; Jiang, D. Measurements of laminar burning velocities and flame stability analysis for dissociated methanol-air-diluent mixtures at elevated temperatures and pressures. Int. J. Hydrogen Energy 2009, 34 (11), 48624875.

(119) Zhang, Y.; Shen, W.; Fan, M.; Zhang, H.; Li, S. Laminar flame speed studies of lean premixed $\mathrm{H}_{2} / \mathrm{CO} /$ air flames. Combust. Flame 2014, 161 (10), 2492-2495.

(120) Zsély, I. G.; Zádor, J.; Turányi, T. Uncertainty analysis of updated hydrogen and carbon monoxide oxidation mechanisms. Proc. Combust. Inst. 2005, 30 (1), 1273-1281.

(121) Kalitan, D. M.; Petersen, E. L. Ignition and oxidation of lean $\mathrm{CO} / \mathrm{H}_{2}$ fuel blends in air. Proceedings of the 41st AIAA/ASME/SAE/ ASEE Joint Propulsion Conference and Exhibit; Tucson, AZ, July 11-13, 2005.

(122) Burke, M. P.; Qin, X.; Ju, Y.; Dryer, F. L. Measurements of hydrogen syngas flame speeds at elevated pressures. Proceedings of the 5th U.S. Combustion Meeting; San Diego, CA, March 25-28, 2007.

(123) Krejci, M. C.; Mathieu, O.; Vissotski, A. J.; Ravi, S.; Sikes, T. G.; Petersen, E. L.; Keromnes, A.; Metcalfe, W.; Curran, H. J. Laminar flame speed and ignition delay time data for the kinetic modeling of hydrogen and syngas fuel blends. Proceedings of the ASME Turbo Expo 2012: Turbine Technical Conference and Exposition; Copenhagen, Denmark, June 11-15, 2012; p 931.

(124) Krejci, M. C.; Vissotski, A. J.; Ravi, S.; Metcalfe, W. K.; Kéromnès, A.; Curran, H. J.; Petersen, E. L. Effect of steam dilution on laminar flame speeds of syngas fuel blends at elevated pressures and temperatures. Proceedings of the Spring Technical Meeting of the Central States Section of the Combustion Institute; Dayton, OH, April 22-24, 2012.

(125) Weng, W. B.; Wang, W.; He, Y.; Zhou, Y. J.; Zhou, J. H.; Cen, K. F. $\mathrm{H}_{2} / \mathrm{CO}$ syngas laminar burning velocity measurement using Teflon coated heat flux burner. Proceedings of the European Combustion Meeting; Lund, Sweden, June 25-28, 2013.

(126) Ranzi, E.; Sogaro, A.; Gaffuri, P.; Pennati, G.; Faravelli, T. A wide range modeling study of methane oxidation. Combust. Sci. Technol. 1994, 96 (4-6), 279-325.

(127) Turányi, T.; Nagy, T.; Zsély, I. G.; Cserháti, M.; Varga, T.; Szabó, B. T.; Sedyó, I.; Kiss, P. T.; Zempléni, A.; Curran, H. J. Determination of rate parameters based on both direct and indirect measurements. Int. J. Chem. Kinet. 2012, 44 (5), 284-302.

(128) Frenklach, M.; Packard, A.; Garcia-Donato, G.; Paulo, R.; Sacks, J. Comparison of statistical and deterministic frameworks of uncertainty quantification. SIAM/ASA J. Uncertainty Quantification 2016, 4 (1), 875-901.

(129) Wang, H.; Sheen, D. A. Combustion kinetic model uncertainty quantification, propagation and minimization. Prog. Energy Combust. Sci. 2015, 47, 1-31.

(130) You, X.; Russi, T.; Packard, A.; Frenklach, M. Optimization of combustion kinetic models on a feasible set. Proc. Combust. Inst. 2011, 33 (1), 509-516.

(131) Davidson, D. F.; Hanson, R. K. Interpreting shock tube ignition data. Proceedings of the WSSCI Fall 2003 Meeting; Los Angeles, CA, Oct 20-21, 2003.

(132) Dryer, F. L.; Chaos, M. Ignition of syngas/air and hydrogen/air mixtures at low temperatures and high pressures: Experimental data interpretation and kinetic modeling implications. Combust. Flame 2008, 152 (1-2), 293-299.

(133) Frenklach, M.; Bornside, D. E. Shock-initiated ignition in methane-propane mixtures. Combust. Flame 1984, 56 (1), 1-27.

(134) Frenklach, M.; Li Kwok Cheong, C. K.; Oran, E. S. LDV measurements of gas flow behind reflected shocks. In Dynamics of Flames and Reactive Systems; Soloukhin, R. I., Oppenheim, A. K.,
Bowen, J. R., Manson, N., Eds.; American Institute of Aeronautics and Astronautics: New York, 1985; pp 722-735, DOI: 10.2514/ 5.9781600865701.0722.0735.

(135) Grogan, K. P.; Ihme, M. Weak and strong ignition of hydrogen/oxygen mixtures in shock-tube systems. Proc. Combust. Inst. 2015, 35 (2), 2181-2189.

(136) Ihme, M. On the role of turbulence and compositional fluctuations in rapid compression machines: Autoignition of syngas mixtures. Combust. Flame 2012, 159 (4), 1592-1604.

(137) Petersen, E. L.; Hanson, R. K. Nonideal effects behind reflected shock waves in a high-pressure shock tube. Shock Waves 2001, 10 (6), 405-420.

(138) Petersen, E. L.; Rickard, M. J. A.; Crofton, M. W.; Abbey, E. D.; Traum, M. J.; Kalitan, D. M. A facility for gas- and condensedphase measurements behind shock waves. Meas. Sci. Technol. 2005, 16 (9), 1716-1729.

(139) Urzay, J.; Kseib, N.; Davidson, D. F.; Iaccarino, G.; Hanson, R. $\mathrm{K}$. Uncertainty-quantification analysis of the effects of residual impurities on hydrogen-oxygen ignition in shock tubes. Combust. Flame 2014, 161 (1), 1-15.

(140) Meyer, J. W.; Oppenheim, A. K. On the shock-induced ignition of explosive gases. Symp. Combust., [Proc.] 1971, 13 (1), 1153-1164.

(141) Hughes, K. J.; Turányi, T.; Clague, A. R.; Pilling, M. J. Development and testing of a comprehensive chemical mechanism for the oxidation of methane. Int. J. Chem. Kinet. 2001, 33 (9), 513-538.

(142) Ripley, D. L.; Gardiner, W. C. Shock-tube study of the hydrogen-oxygen reaction. II. Role of exchange initiation. J. Chem. Phys. 1966, 44 (6), 2285-2296.

(143) Jachimowski, C. J.; Houghton, W. M. Shock-tube study of the initiation process in the hydrogen-oxygen reaction. Combust. Flame 1971, 17 (1), 25-30.

(144) Michael, J. V.; Sutherland, J. W.; Harding, L. B.; Wagner, A. F. Initiation in $\mathrm{H}_{2} / \mathrm{O}_{2}$ : Rate constants for $\mathrm{H}_{2}+\mathrm{O}_{2} \rightarrow \mathrm{H}+\mathrm{HO}_{2}$ at high temperature. Proc. Combust. Inst. 2000, 28 (2), 1471-1478.

(145) Filatov, M.; Reckien, W.; Peyerimhoff, S. D.; Shaik, S. What are the reasons for the kinetic stability of a mixture of $\mathrm{H}_{2}$ and $\mathrm{O}_{2}$ ? J. Phys. Chem. A 2000, 104, 12014-12020.

(146) Karkach, S. P.; Osherov, V. I. Ab initio analysis of the transition states on the lowest triplet $\mathrm{H}_{2} \mathrm{O}_{2}$ potential surface. J. Chem. Phys. 1999, 110 (24), 11918.

(147) Bates, R. W.; Golden, D. M.; Hanson, R. K.; Bowman, C. T. Experimental study and modeling of the reaction $\mathrm{H}+\mathrm{O}_{2}+\mathrm{M} \rightarrow$ $\mathrm{HO}_{2}+\mathrm{M}\left(\mathrm{M}=\mathrm{Ar}, \mathrm{N}_{2}, \mathrm{H}_{2} \mathrm{O}\right)$ at elevated pressures and temperatures between 1050 and 1250 K. Phys. Chem. Chem. Phys. 2001, 3 (12), 2337-2342.

(148) Fernandes, R. X.; Luther, K.; Troe, J.; Ushakov, V. G. Experimental and modelling study of the recombination reaction $\mathrm{H}+$ $\mathrm{O}_{2}(+\mathrm{M}) \rightarrow \mathrm{HO}_{2}(+\mathrm{M})$ between 300 and $900 \mathrm{~K}, 1.5$ and 950 bar, and in the bath gases $\mathrm{M}=\mathrm{He}, \mathrm{Ar}$, and $\mathrm{N}_{2}$. Phys. Chem. Chem. Phys. 2008, 10 (29), 4313-4321.

(149) Ibraguimova, L. B.; Smekhov, G. D.; Shatalov, O. P. Comparative Analysis of the Rates of Chemical Reactions Describing the Combustion of Hydrogen-Oxygen Mixtures; http://www.chemphys.edu. $\mathrm{ru} / \mathrm{media} /$ files/2009-06-29-001 .pdf.

(150) Michael, J. V.; Su, M. C.; Sutherland, J. W.; Carroll, J. J.; Wagner, A. F. Rate constants for $\mathrm{H}+\mathrm{O}_{2}+\mathrm{M} \rightarrow \mathrm{HO}_{2}+\mathrm{M}$ in seven bath gases. J. Phys. Chem. A 2002, 106 (21), 5297-5313.

(151) Sellevag, S. R.; Georgievskii, Y.; Miller, J. A. The temperature and pressure dependence of the reactions $\mathrm{H}+\mathrm{O}_{2}(+\mathrm{M}) \rightarrow \mathrm{HO}_{2}(+\mathrm{M})$ and $\mathrm{H}+\mathrm{OH}(+\mathrm{M}) \rightarrow \mathrm{H}_{2} \mathrm{O}(+\mathrm{M})$. J. Phys. Chem. A 2008, 112 (23), 5085-5095.

(152) Troe, J. Detailed modeling of the temperature and pressure dependence of the reaction $\mathrm{H}+\mathrm{O}_{2}(+\mathrm{M}) \rightarrow \mathrm{HO}_{2}(+\mathrm{M})$. Proc. Combust. Inst. 2000, 28 (2), 1463-1469.

(153) Cohen, N.; Westberg, K. R. Chemical kinetic data sheets for high-temperature chemical reactions. J. Phys. Chem. Ref. Data 1983, 12 (3), 531. 
(154) Koike, T. Shock Tube Studies of the $\mathrm{H}_{2}-\mathrm{O}_{2}-\mathrm{CO}$ Reaction by Atomic Resonance Absorption Spectroscopy. Bull. Chem. Soc. Jpn. 1991, 64 (6), 1726-1730.

(155) Rawlins, W. T.; Gardiner, W. C. Rate constant for carbon monoxide + molecular oxygen $=$ carbon dioxide + atomic oxygen from 1500 to 2500 .deg. K. Reevaluation of induction times in the shockinitiated combustion of hydrogen-oxygen-carbon monoxide-argon mixtures. J. Phys. Chem. 1974, 78 (5), 497-500.

(156) Sharipov, A. S.; Starik, A. M. Theoretical study of the reaction of carbon monoxide with oxygen molecules in the ground triplet and singlet delta states. J. Phys. Chem. A 2011, 115 (10), 1795-1803.

(157) Thielen, K.; Roth, P. Stoßtwellenuntersuchungen zum Start der Reaktion $\mathrm{CO}+\mathrm{O}_{2}$. Ber. Bunsenges. Phys. Chem. 1983, 87 (10), 920-925.

(158) Tsang, W.; Hampson, R. F. Chemical kinetic data base for combustion chemistry. Part I. Methane and related compounds. J. Phys. Chem. Ref. Data 1986, 15 (3), 1087.

(159) Christoffel, K. M.; Bowman, J. M. Three reaction pathways in the $\mathrm{H}+\mathrm{HCO} \rightarrow \mathrm{H}_{2}+\mathrm{CO}$ reaction. J. Phys. Chem. A 2009, 113 (16), $4138-4144$.

(160) Friedrichs, G.; Herbon, J. T.; Davidson, D. F.; Hanson, R. K. Quantitative detection of HCO behind shock waves: The thermal decomposition of HCO. Phys. Chem. Chem. Phys. 2002, 4 (23), 57785788.

(161) Troe, J.; Ushakov, V. G. Classical trajectory study of the reaction between H and HCO. J. Phys. Chem. A 2007, 111 (29), 6610-6614.

(162) Joshi, A. V.; Wang, H. Master equation modeling of wide range temperature and pressure dependence of $\mathrm{CO}+\mathrm{OH} \rightarrow$ products. Int. J. Chem. Kinet. 2006, 38 (1), 57-73.

(163) Li, J.; Wang, Y.; Jiang, B.; Ma, J.; Dawes, R.; Xie, D.; Bowman, J. M.; Guo, H. Communication: A chemically accurate global potential energy surface for the $\mathrm{HO}+\mathrm{CO} \rightarrow \mathrm{H}+\mathrm{CO}_{2}$ reaction. J. Chem. Phys. 2012, 136 (4), 041103.

(164) Colberg, M.; Friedrichs, G. Room temperature and shock tube study of the reaction $\mathrm{HCO}+\mathrm{O}_{2}$ using the photolysis of glyoxal as an efficient HCO source. J. Phys. Chem. A 2006, 110 (1), 160-170.

(165) Fassheber, N.; Friedrichs, G.; Marshall, P.; Glarborg, P. Glyoxal oxidation mechanism: Implications for the reactions $\mathrm{HCO}+\mathrm{O}_{2}$ and $\mathrm{OCHCHO}+\mathrm{HO}_{2}$. J. Phys. Chem. A 2015, 119 (28), 7305-7315.

(166) DeSain, J. D.; Jusinski, L. E.; Ho, A. D.; Taatjes, C. A. Temperature dependence and deuterium kinetic isotope effects in the $\mathrm{HCO}(\mathrm{DCO})+\mathrm{O}_{2}$ reaction between 296 and $673 \mathrm{~K}$. Chem. Phys. Lett. 2001, 347 (1-3), 79-86.

(167) Timonen, R. S.; Ratajczak, E.; Gutman, D. Kinetics of the reactions of the formyl radical with oxygen, nitrogen dioxide, chlorine, and bromine. J. Phys. Chem. 1988, 92 (3), 651-655.

(168) Hsu, C. C.; Mebel, A. M.; Lin, M. C. Ab initio molecular orbital study of the $\mathrm{HCO}+\mathrm{O}_{2}$ reaction: Direct versus indirect abstraction channels. J. Chem. Phys. 1996, 105 (6), 2346.

(169) Mittal, G.; Sung, C. J.; Fairweather, M.; Tomlin, A. S.; Griffiths, J. F.; Hughes, K. J. Significance of the $\mathrm{HO}_{2}+\mathrm{CO}$ reaction during the combustion of $\mathrm{CO}+\mathrm{H}_{2}$ mixtures at high pressures. Proc. Combust. Inst. 2007, 31 (1), 419-427.

(170) You, X.; Wang, H.; Goos, E.; Sung, C.-J.; Klippenstein, S. J. Reaction kinetics of $\mathrm{CO}+\mathrm{HO}_{2} \rightarrow$ products: $\mathrm{Ab}$ initio transition state theory study with master equation modeling. J. Phys. Chem. A 2007, 111 (19), 4031-4042.

(171) Timonen, R. S.; Ratajczak, E.; Gutman, D.; Wagner, A. F. The addition and dissociation reaction atomic hydrogen + carbon monoxide.dblharw. oxomethyl. 2. Experimental studies and comparison with theory. J. Phys. Chem. 1987, 91 (20), 5325-5332.

(172) Krasnoperov, L. N.; Chesnokov, E. N.; Stark, H.; Ravishankara, A. R. Unimolecular dissociation of formyl radical, $\mathrm{HCO} \rightarrow \mathrm{H}+\mathrm{CO}$, studied over 1-100 bar pressure range. J. Phys. Chem. A 2004, 108 (52), 11526-11536.

(173) Cribb, P. H.; Dove, J. E.; Yamazaki, S. A kinetic study of the pyrolysis of methanol using shock tube and computer simulation techniques. Combust. Flame 1992, 88 (2), 169-185.
(174) Westmoreland, P. R.; Howard, J. B.; Longwell, J. P.; Dean, A. M. Prediction of rate constants for combustion and pyrolysis reactions by bimolecular QRRK. AIChE J. 1986, 32 (12), 1971-1979.

(175) Troe, J. Thermal dissociation and recombination of polyatomic molecules. Symp. Combust., [Proc.] 1975, 15 (1), 667-680.

(176) Jasper, A. W.; Dawes, R. Non-Born-Oppenheimer State-toState Dynamics of the $\mathrm{N}\left({ }^{2} \mathrm{D}\right)+\mathrm{H}_{2} \rightarrow \mathrm{NH}\left(\tilde{\mathrm{X}}^{3} \Sigma^{-}\right)+\mathrm{H}$ Reaction: Influence of the Renner-Teller Coupling. J. Chem. Phys. 2013, 139 (15), 154313.

(177) Kathrotia, T.; Fikri, M.; Bozkurt, M.; Hartmann, M.; Riedel, U.; Schulz, C. Study of the $\mathrm{H}+\mathrm{O}+\mathrm{M}$ reaction forming $\mathrm{OH}^{*}$ : Kinetics of $\mathrm{OH}^{*}$ chemiluminescence in hydrogen combustion systems. Combust. Flame 2010, 157 (7), 1261-1273.

(178) Kee, R. J.; Rupley, F. M.; Miller, J. A. CHEMKIN-II: A FORTRAN Chemical Kinetics Package for the Analysis of Gas-Phase Chemical Kinetics; Sandia National Laboratories: Albuquerque, NM, 1993; SAND89-8009B, UC-706.

(179) Kintech Lab, Ltd. Chemical Workbench; http://www. kintechlab.com/.

(180) Hegde, A.; Li, W.; Oreluk, J.; Packard, A.; Frenklach, M. Consistency Analysis for Massively Inconsistent Datasets in Bound-toBound Data Collaboration; http://arxiv.org/abs/1701.04695.

(181) Manion, J. A.; McGivern, W. S. The importance of relative reaction rates in the optimization of detailed kinetic models. Int. J. Chem. Kinet. 2016, 48 (7), 358-366.

(182) Yeates, D. R.; Li, W.; Westmoreland, P. R.; Speight, W.; Russi, T.; Packard, A.; Frenklach, M. Integrated data-model analysis facilitated by an instrumental model. Proc. Combust. Inst. 2015, 35, 597-605.

(183) Egolfopoulos, F. N.; Hansen, N.; Ju, Y.; Kohse-Höinghaus, K.; Law, C. K.; Qi, F. Advances and challenges in laminar flame experiments and implications for combustion chemistry. Prog. Energy Combust. Sci. 2014, 43, 36-67. 